A.R. Carrasco ${ }^{12}$, Ó. Ferreira ${ }^{1}$, D. Roelvink ${ }^{345}$

${ }^{1}$ CIMA, Universidade do Algarve, Campus de Gambelas, 8005-139, Faro, Portugal Campus de Gambelas, Ed. 7, 8005-139, Faro, Portugal, azarcos@ualg.pt, oferreir@ualg.pt ${ }^{2}$ corresponding author: azarcos@ualg.pt

${ }^{3}$ UNESCO-IHE, P.O. box 3015, 2601 DA Delft, the Netherlands, d.roelvink@unesco-ihe.org ${ }^{4}$ Delft University of Technology, Faculty of Civil Engineering and Geosciences, Section Hydraulic Engineering, P.O. Box 5048, 2600 GA, Delft, The Netherlands ${ }^{5}$ Deltares, Department ZKS and HYE, P.O. Box 177, 2600 MH, Delft, The Netherlands

\title{
12 Abstract
}

13 Sea-level rise (SLR) poses a particularly ominous threat to human habitations and 14 infrastructure in the coastal zone because 10\% of the world's population (about 7 billion people) live in low-lying coastal regions within $10 \mathrm{~m}$ elevation of sea level. This paper reviews the patterns and effects of SLR in coastal lagoons, highlighting the practical difficulties of assessing the consequences of relative SLR (RSLR), as well as the issues that require further research. This review discusses the projected SLR rates of the Intergovernmental Panel on Climate Change as well as the actual strategies for facing the impacts of RSLR at a local scale. It is shown that the major sources of uncertainty are the projected mean SLR estimates and how and when RSLR will manifest itself at different scales in coastal lagoon systems. Most of the studies reviewed herein articulate a 'defence' mechanism of barriers in coastal lagoons by landward barrier retreat through continuous migration. Moreover, a gradual change in basin hypsometry is reported during the retreat process, transforming supratidal areas into open-water and intertidal environments where there is no available sediment to counter the effects of RSLR. Studies of the impacts of RSLR usually adopt modelling scenarios as key tools.

RSLR also bears drastic consequences in the social-economic frame. Related impacts are already evident for many different coastal lagoons, but the way in which such effects can be mitigated is still not evident, particularly because most of the adaptation measures for facing RSLR will involve large and ongoing costs. Nevertheless, the need to adapt to RSLR is obvious, and much more research about adaptation measures is still needed, taking into consideration not only the physical and ecological systems but also social, cultural, and economic impacts. Future challenges include a downscaling of SLR approaches from the global level to regional and local levels, with a detailed application of coastal evolution prediction to each coastal lagoon system.

Key-words: sea-level rise, coastal lagoons, coastal evolution, barriers, adaptation 
Sea-level rise (SLR) is among the most important yet complex and often misunderstood aspects of climate change. Not surprisingly, there have been many recent reviews of SLR, including those of Cazenava and Llovel (2009), Willis et al. (2010), Church and White (2011), Gehrels et al. (2011), Nicholls et al. (2011), and Pfeffer (2011). The question of how much and when sea-level rise will occur in the future has been prominent since the earliest US Environmental Protection Agency and initial Intergovernmental Panel on Climate Change (IPCC) estimates of climate change and its consequences (IPCC, 2001). The most recent projections by the IPCC (IPCC, 2014) consider a scenario of very high emissions, and predict a global rise of $52-98 \mathrm{~cm}$ by the end of this century, which would threaten the viability of many coastal cities (Fig. 1).

What matters most to the coastal morphological equilibrium is not the global-mean projected SLR rate itself, but the local change in the observed relative sea-level rise (RSLR). Possible causes of regional sea-level variations include gravitational effects resulting from land ice mass changes, thermal expansion, and ocean dynamics (Slange et al., 2012). RSLR has already been identified in the literature (e.g., Church and White, 2006; Kirwan and Murray, 2008; Kirwan et al., 2008; Chust et al., 2009; Gillanders et al., 2011) as a critical variable for the establishment and maintenance of biotic coastal communities, as a threat to biodiversity, and as being responsible for the increasing magnitude and spatial extent of storm surge flood hazard, amongst other issues. Indeed, the impacts of RSLR are already evident in several different coastal regions (e.g., IPCC, 2007; Nicholls et al., 2007; Fitzgerald et al., 2008). However, regarding morphological feedback, there is still a lack of critical examination of the dimensions of change to come (Orford and Pethick, 2006). Perhaps the most serious and widely recognized issue facing coastal conservation is the impact of RSLR on coastal landforms in coastal lagoons and estuaries. Coastal lagoons are here considered as "inland water bodies separated from the ocean by a barrier, connected to the ocean by one or more restricted inlets which remain open at least intermittently, and have water depths which seldom exceed a few metres" (Adlam, 2014). About 32,000 lagoons are reported along 13\% of the world's coastline (Carter and Woodroffe, 1994), with a coastline contribution estimated at $17.6 \%$ for North America, $12.2 \%$ for South America, 5.3\% for Europe, $17.9 \%$ for Africa, $13.8 \%$ for Asia, and $11.4 \%$ for Australia (Barnes, 1980).

The size of coastal lagoons varies substantially, with surface areas ranging up to $10,200 \mathrm{~km}^{2}$, as in the case of Lagoa dos Patos in Brazil (Pilkey et al., 2009). Coastal lagoons are relatively young features, have formed over the last 5000-7000 years, and are often short lived over geological timescales because of sedimentation (Martin and Dominguez, 1994). Most coastal lagoons are maintained only by the protection afforded by barriers and spits, presenting very peculiar feedbacks to RSLR (List et al., 1997). Although the responses to the 
effects of RSLR observed in coastal lagoons are manifest in different contexts (e.g., physical, ecological, and economic) and over different time scales, only the physical changes (inundation and sediment supply) are discussed in the present work.

Geological observations reveal that many barrier systems worldwide have been able to keep pace with RSLR for thousands of years (McBride et al., 2013). These systems can have spatially distinct responses to RSLR, as in the case of the Gulf of Mexico, which is composed of several bay/lagoon stretches and barriers, where previous studies (e.g., Troiani et al., 2011) have reported rapid and dramatic morphological changes resulting from RSLR but also spatial differences in the response. Other case studies showing the influence of RSLR on lagoons and/or estuaries include Lagoa dos Patos, Brazil (e.g., Toldo et al., 2000), Lake Illawarra and St Georges Basin, New South Wales, Australia (e.g., Sloss et al., 2006), Venice Lagoon, Italy (e.g., Ferla et al., 2007), Pamlico-Albemarle Sound, North Carolina, United States (e.g., Pilkey et al., 2009), Wadden Sea, Netherlands/Germany (e.g., Dissanayake et al., 2012), Ria Formosa, Portugal (e.g., Andrade et al., 2004), Vistula Lagoon, Baltic Sea (e.g., Navrotskaya and Chubarenko, 2013), and Manzala Lagoon, Egypt (Frihy and El-Sayed, 2013).

In addition to the direct link between RSLR and physical systems, morphological changes resulting from RSLR can also lead to drastic consequences in the social-economic frame (Nicholls and Tol, 2006). Anthoff et al. (2006), in a study dedicated to all types of coast, detailed the economic and social implications of large rises in sea level during the twenty-first century and beyond (the main outcomes are shown in Fig. 2). Those authors estimate that 145 million people live within $1 \mathrm{~m}$ of present-day mean sea level. Regionally, the most threatened lands are North America, central Asia, and unpopulated Arctic coastlines. In terms of threatened population, eastern and southern Asia dominates (Fig. 2) owing to their large populated delta areas. In terms of economies, eastern Asia, Europe, and North America dominate, although this distribution most likely will change during the twenty-first century (Anthoff et al., 2006).

Understanding how RSLR is likely to affect coastal regions (in particular lagoons) and consequently how society will choose to address this issue in the short term in ways that are sustainable for the long term, is a major challenge for both scientists and coastal policymakers and managers (CCSP, 2009). The need for adaptation to climate change is evident, and much more research is still required if our understanding of these important issues is to be refined. According to Nicholls et al. (2006), the average annual costs for protecting coastlines are assumed to be a linear function of the rate of RSLR and of the proportion of the coast that is protected. The costs increase by an order of magnitude if the rate of RSLR is higher than 1 $\mathrm{cm} \mathrm{yr}^{-1}$ (i.e., protection costs are much higher for the $1 \mathrm{~m}$ and $2 \mathrm{~m}$ rise scenarios than for the $0.5 \mathrm{~m}$ scenarios). Therefore, to predict impacts, we need to be aware of changes (Nicholls and 
113 Tol, 2006; Woodroffe and Murray-Wallace, 2012). Several questions still need to be

114 answered, the most important of which are: To what extent are the observed changes locally

115 important from the natural and social-economic-cultural points of view? And, to what extent

116 will global mitigation measures prove adequate for local cases? These questions are often

117 associated with a difficulty in conceptualizing and quantifying the main expected responses

118 (from the natural and social-economic-cultural points of view).

119 The present work reviews the previous research on coastal lagoon evolution

120 associated with RSLR and discusses the main modelling attempts for forecasting induced

121 changes in coastal lagoon systems. This review is oriented more towards the most relevant

122 papers on the topic of SLR and induced morphological changes inside coastal lagoon systems.

123 Therefore, emphasis is placed on the physical constraints (morphological changes in intertidal

124 areas) rather than on the biological/ecological processes or social-economic - cultural

125 consequences. Three foci to the review are presented: (a) summarizing the main approaches

126 used in predicting medium- to long-term trends in SLR; (b) identifying the main evolutionary

127 trends of coastal lagoons and the tools used to examine such trends; and (c) highlighting the

128 aspects that require further research.

2. SLR scenarios and key uncertainties

131 There has been much discussion about projected (and the sources of projection) $v s$.

132 measured SLR rates. Which rates should coastal scientists and managers apply in their

133 studies, and what is the degree of confidence of such forecasts, are still open questions. Most

134 of the studies conducted on these aspects have been based on scenarios, which allow

135 assessments to be made of developments in complex systems that are either inherently

136 unpredictable or which have high scientific uncertainties. The reliability of and the difficulties

137 associated with the development and use of scenarios have emerged as important problems

138 for and constraints on impact and adaptation studies (Nicholls et al., 2014). As an example,

139 Figure 3A illustrates the SLR scenario variability for the end of this century (period 2081-

140 2100) for just one (RCP4.5, RCP - representative concentration pathway) of the recent SLR

141 projections released by IPCC (2014); the three panels clearly show different sea-level

142 changes, dependent on the model uncertainty.

143 In the overall context of SLR forecasts, two inherent uncertainties are involved. The

144 first (the 'scenario uncertainty') arises from our limited knowledge of the future social,

145 economic, and technological development of the world, and of the consequent greenhouse-gas

146 emissions. Therefore, a range of plausible scenarios has been used to describe the way in

147 which emissions may change in the future. The second uncertainty (the 'model uncertainty')

148 is related to shortcomings in the present knowledge of the science of climate change, due

149 partly to the fact that we do not know exactly the present climate state (the 'initial 
conditions'), and due partly to the fact that no model provides a perfect representation of the real world (Hunter, 2010).

Although there are yet no complete simulations of regional ocean temperature changes and of the response of ice sheets to realistic climate change forcing, publications to date have allowed an assessment of the likely range of SLR for the twenty-first century (IPCC, 2014). Hindcast predictions computing the sum of observed contributions to SLR are in good agreement with the observed rise (Fig. 3B).

Direct comparisons between the values from the IPCC's 4th assessment report published in 2007 (AR4) and the newly released 5th Assessment Report (AR5; IPCC, 2013 and 2014) are difficult, because underlying scenarios have been significantly revised (Horton et al., 2014). The recent AR5 projected a 'likely' (i.e., a 66\% likelihood range) global-average sea-level rise of 28-61 cm for a scenario of a drastic reduction in emissions (RCP 2.6) and 52-98 cm in the case of an unmitigated increase in emissions (RCP 8.5; Table 1; Fig. 1).

Table 1. Global SLR by the year 2100 as projected by the IPCC's AR5. The values are relative to the mean for 1986-2005, so $1 \mathrm{~cm}$ should be subtracted to obtain values relative to the year 2000 (source Horton et al., 2014).

\begin{tabular}{|l|c|c|}
\hline Scenario designation* & Mean (cm) & Range (cm) \\
\hline RCP2.6 & 44 & $28-61$ \\
\hline RCP4.5 & 53 & $36-71$ \\
\hline RCP6.0 & 55 & $38-73$ \\
\hline RCP8.5 & 74 & $52-98$ \\
\hline
\end{tabular}

*for more details about each scenario, please see IPCC AR5 (http://www.ipcc.ch/report/ar5/)

The key findings of IPCC AR5 for past and future sea levels can be summarized as: (1) global sea level is rising, (2) this rise has accelerated since pre-industrial times, and (3) the rise will accelerate further during this century (in fact, it will continue to rise during the twenty-first century and beyond, as shown in Fig. 3B). For the first few decades of the twenty-first century, regional sea-level change will be dominated by climate variability superimposed on the climate change signal. For an unmitigated future rise in emissions (RCP8.5), IPCC (2014) expects between 0.5 and $1.0 \mathrm{~m}$ of SLR by the end of the twenty-first century (Figs 1 and 3B). Taking into consideration the mean SLR for the RCP8.5 scenario

177 (Table 1), the estimate is $74 \mathrm{~cm}$, which means an expected SLR of more than four times larger than that experienced during the twentieth century (17 cm; IPCC, 2014). These scenarios reflect the large inertia in sea-level response: it is difficult for SLR slow down again once it has been initiated (IPCC, 2013). 
As scientific understanding improves, a common objective is to narrow the range of uncertainty in the predictions of SLR (even in AR5). There still exists a low (but not negligible) risk of much larger rises (>1 m) in sea level, which are of particular relevance to impact and adaptation assessment (Nicholls et al., 2014), and this issue has not yet been resolved by the IPCC. For coastal planning, SLR needs to be considered in a risk management framework, requiring knowledge of the frequency of sea-level variability in future climates, projected changes in mean sea level, and the uncertainty in sea-level projections (Hunter, 2012). For coastal evolution, other issues such as the compaction of sediments (and subsidence) and the changing supply of these sediments to maintain the height of coastal systems must also be considered (see Section 3).

A persistent major source of uncertainty, in addition to the uncertainty contained in

192 the projected mean SRL values, is how and when SLR will manifest itself at different scales

193 (Nicholls and Klein, 2005), especially at the local scale (RSLR). Assuming that we are

194 prepared to face RSLR, such information is vital to inform policy-makers and decision-

195 makers when determining whether measures have to be taken to protect coastal communities from sea-level rise.

Indeed, the IPCC's projections have been limited to a global mean value and do not consider the large regional variations induced by various other local processes, leading to non-uniform underestimations of RSLR. The results of Slangen et al. (2012), which considered the sea-level scenarios advanced by AR4, show that estimates of RSLR differ substantially from the global mean SLR. The AR5 report underlines that global average projected scenarios are indeed useful approximations that reflect the contribution of climatic processes, and represent good estimates of sea-level change at many coastal locations. At the same time, the IPCC recognizes that the various regional processes can cause large departures from the global average value; however, a comprehensive discussion of this issue is lacking in the report.

\section{Time scales and length scales of coastal evolution}

The extreme non-linearity of coastal sedimentary systems in coastal lagoons often hinders our ability to make predictions of coastal change at larger scales, particularly because the temporal 'upscaling' of processes from smaller scales to those relevant to coastal

212 management (or vice versa) is a difficult (and sometimes ill-advised) practice, and limits our

213 capacity to predict future coastal change (Ashton et al., 2007). Coastal lagoons enclose

214 morphologies presenting different spatial scales, ranging from bed forms ( $\sim \mathrm{cm}$ to $\mathrm{m}$ ) such as

215 ripples and dunes, to channel-shoal patterns, vegetated salt marshes, and full basins $(\sim 1-100$

216 km, Carter and Woodroffe, 1994; Perillo, 1995; Hibma et al., 2004), which have complex

217 evolutions that do not follow a specific formula or respond in a linear fashion to forcing 
218 factors. Barriers and channels are constrained by boundary conditions, and the cycle of

219 evolution taking place is bound by the principle of Markovian inheritance, whereby the

220 product of previous changes (i.e., antecedent topography and hydrology) provides the initial

221 conditions upon which future evolutionary processes build (Cowell and Thom, 1994). Cowell

222 and Thom (1994) developed a very appropriate account of morphodynamic processes and

223 coastal domain evolution with respect to different time and space scales (Fig. 4). Their

224 conceptual model illustrates the interaction between operating hydrodynamic and sediment

225 dynamic processes and the morphology (topography) of the coastal area. In this scheme, the

226 longer-term evolution of a coastal lagoon is a function of RSLR, tide height and asymmetry,

227 the resulting spatial gradients of the tide residual sediment transport, and the sediment

228 input/output budget. However, other processes (such as wind waves, mud, and vegetation

229 growth) may also play a significant role.

230 The present study envisages a large-scale length context (tens to hundreds of $\mathrm{km}$ in

231 length) and long-term (decades up to hundreds of years) approaches (Fig. 4). The long-term,

232 large-scale evolution was chosen because lagoon evolution over such temporal and spatial

233 scales has not been widely studied or synthesised. Moreover, the most significant studies and

234 their outcomes are very recent, covering the past two decades, and there is a need to integrate

235 and validate these studies.

\section{Morphological effects of RSLR in coastal lagoons}

The wide variety of spatial and temporal scales involved in coastal basins makes their morphodynamic long-term behaviour very complex (Dastgheib et al., 2008). The whole basin system (mega-scale), includes barriers, inlets, basins, and marshes, and embraces different morphological elements (macro-scale) and various morphological features inside each element (meso-scale) responding differently, both temporally and spatially, to physical changes (Ranasinghe et al., 2012). The geological evolution of a lagoon is typically expressed in terms of the rate of basin fill through sedimentation. It is thus helpful to consider the lagoon fill in terms of maturity (Roy et al., 2001; Smith, 2001). Immature lagoons are newly inundated depositional basins in which the entire volume of the water body is available to accommodate sediment (i.e., the volume of empty space behind the barrier that would need to be filled with sediment in order to reach sea level, hereafter referred to as accommodation space). In contrast, mature lagoons are entirely filled with sediment, accommodation space has been exhausted, and river discharge flows directly to the coast. Most processes operating within lagoons affect the degree of maturity through the creation and consumption of accommodation space (Adlam, 2014). The rate of consumption of accommodation space is dependent on the rate of sediment supply (Roy et al., 1980; Boyd et al., 1992). 


\subsection{RSLR and the evolution of barriers and inlets}

As sea level rises, barrier islands tend to migrate (e.g., Hoyt, 1967; Swift, 1975; Bruun, 1988; Zhang et al., 2004; Masetti et al., 2008; Moore et al., 2010). Besides RSLR, other factors that control rates of island migration include the underlying geology (e.g., Riggs et al., 1995), the stratigraphy (e.g., Storms et al., 2002; Moore et al., 2010), sediment grain size (e.g., Storms et al., 2002; Masetti et al., 2008), substrate slope (Storms et al., 2002; Wolinsky and Murray, 2009; Moore et al., 2010), and substrate erodibility (Moore et al., 2010).

Although our overall understanding of how barrier islands respond to climate change continues to improve, little is known about how the connectivity of the two constituent landscape systems (i.e., barriers and inlets) affects the evolution of coupled barrier-marsh systems under changing conditions (Walters et al., 2014). Under rising sea level, barriers will lose areal extent at a rate equal to that at which the barrier island rolls over the marsh platform, unless the marsh progrades into the bay or up the mainland slope as it is flooded by the rising sea level (Moore et al., 2014). Recent findings from Watson et al. (2011) and Walters et al. (2014) suggest that barriers backed by marshes have the added benefit of reduced accommodation space, which allows an island to remain "perched" on the marsh, compared to islands backed by open bays, which must migrate further landwards to maintain elevation relative to sea level. In fact, marsh-backed islands appear to be less vulnerable to rising sea level than do bay-backed islands, because they are able to maintain a more offshore position without a significant contribution of sand from alongshore transport or from the shoreface (Walters et al., 2014).

An increase in the rate of RSLR will gradually change the hypsometry of the backbarrier, transforming supratidal areas to open-water and intertidal environments, as observed by Ashton et al. (2007). RSLR will cause changes in inlet geometry or in tidal forcing, affecting the baseline level of transport through the inlet, and thus to the interior (Smith, 2001). Figure 5 illustrates the equilibrium volumes of the elements of an inlet as a function of SLR: with a higher rate of RSLR, the dynamic equilibrium volume of the channel increases and the dynamic equilibrium volume of the ebb-tidal delta decreases. Such trends were obtained by van Goor et al. (2003) for the Dutch Wadden Sea (Fig. 5). Those authors assumed the existence of a dynamic equilibrium to predict critical rates of SLR for inlet/basin systems. In the graph, as the sediment demand for a smaller basin decreases, the inlet adapts more easily to a higher rate of sea-level rise, for the same hydrodynamic and sedimentological conditions. For the basins considered, there was a gradual deepening over time of the tidal basin that prompted an importation of sediment (van Goor et al., 2003). 
292 deficiency in the conceptualization of expected morphological changes and their importance

293 at the regional/local scale that is presented in a straight-forward manner and which can be

294 rapidly assessed by decision-makers. Penland et al. (1988) were amongst the first to

295 conceptualize the long-term scenario response of a low-lying system to RSLR, referring to the

296 system as a delta-type coast (namely, the Mississippi Delta). Focussing more on coastal

297 lagoons, Fitzgerald et al. (2006) developed a conceptual scheme (Fig. 6) that describes the

298 barrier/inlet/basin cell feedback in relation to RSLR, and which can be used to interpret long-

299 term changes in coastal barrier systems. Fitzgerald's (2006) scheme is more complete and

300 more exhaustive than that of Penland et al. (1988), and has wider application. It addresses the

301 fate of mixed-energy barrier coasts found throughout the northeastern coast of the United

302 States, the East Friesian Islands in the North Sea, and the Copper River delta barriers in the

303 Gulf of Alaska, which are characterized by short, fragmented, stubby barrier islands,

304 numerous tidal inlets, well-developed ebb-tidal deltas, and a backbarrier consisting of salt

305 marshes and tidal flats incised by tidal creeks.

306 In essence, the model of Fitzgerald (2006) represents the conversion of marsh to open

307 water, causing an increase in the tidal prism and growth of the ebb shoals (a stable barrier to

308 transgression, Fig. 6). In the model, no additional sediment inflow is considered, and the

309 greater part of the inorganic sediment input is marine. The loss of marshlands increases tidal

310 exchange between the ocean and backbarrier and ultimately changes the hydraulic regime of

311 the tidal inlets. The growth of both ebb- and flood-tidal deltas diminishes the supply of sand

312 along the coast, leading to a fragmentation of the barrier chain and the formation of a

313 transgressive coastal system (stage 3, Fig. 6). Sand is assumed to be lost from the littoral

314 system as it is moved into the backbarrier to form flood shoals (FitzGerald et al., 2006). There

315 is an increase in the tidal prism, which strengthens the tidal currents and enlarges the size of

316 the tidal inlets. During the process of increasing tidal exchange between the backbarrier and

317 ocean, there is the potential for dramatic changes to occur in the inlet shoreline (stage 2, Fig.

318 6). A change from ebb- to flood-dominated inlets, as the marshes and tidal creeks are

319 transformed to open bays, promotes the formation of flood deltas, but does not retard the

320 growth of ebb deltas, because the volume of the flood deltas is dependent on the tidal prism

321 (FitzGerald et al., 2006).

322 Prior to the study of FitzGerald et al. (2006), FitzGerald et al. (1984) had already

323 illustrated with respect to the evolution of the Friesian Islands what can happen to a barrier

324 chain when an alteration of backbarrier hypsometry induces changes in the tidal prism,

325 although the earlier study did not incorporate a relevant conceptual schematisation. During a

326310 year period, the backbarrier area of the Friesian Islands decreased by $30 \%$ due mostly to

327 land reclamation of tidal flat areas along the landward sides of the barriers and along the

328 mainland shore. Secondary losses were attributed to re-curved spit extension into the 
329 backbarrier. These processes resulted in a reduction in the tidal prism and a coincident

330 narrowing of the tidal inlets by 52\% (FitzGerald et al., 1984).

331 Most of the findings of FitzGerald et al. (2006) were subsequently corroborated in the 332 case study of Dissanayake et al. (2012). The investigations of Ganju and Schoellhamer (2010)

333 and Dissanayake et al. (2012) were the first to address the morphodynamic impact of RSLR

334 on inlet systems using a numerical model.

\subsection{RSLR, sediment supply, and basin evolution}

Depending on local basin geometry, RSLR causes sediment import or export (see Friedrichs et al., 1990). In the case of a flood-dominated tidal lagoon, RSLR tends to result in sediment accumulation as a means of restoring the intrinsic dynamic equilibrium of the basin (Dronkers, 1998). Thus, besides the direct barrier and inlet adjustments, RSLR also affects the basin drainage area. Redfield et al. (1965) were the first to provide evidence of concomitant bay infilling and lateral progradation of the intertidal marsh onto sand flats, where existing meandering channels were stabilized by the marsh itself through narrowing of the channels until the flow was concentrated enough to prevent further erosion or deposition.

A relevant conceptualization of tidal basin response to accelerated RSLR, using the Wadden Sea as an example, is expressed in Figure 7. The graph in that figure is consistent with the conceptual model proposed by FitzGerald et al. (2006), and highlights the concept of 'adjustment' inside the tidal basin. The scheme proposed by FitzGerald et al. (2006) is focused mostly on the SLR-inlet-backbarrier relationship, whereas the Louters and Gerritsen (1994) scheme details the steps of adjustment inside the lagoon, namely, regarding the depth of the basin, after an increase in the rate of RSLR. The Louters and Gerritsen (1994) model also assumes that there is a dynamic balance between sediment supply, ecosystems, and changes in sea level; indeed, as stated by the Bruun rule, an equilibrium state is assumed in the periods between sediment basin adjustments to RSLR. Therefore, the system's response to the rise is delayed and the average basin level thereby becomes slightly lower in relation to sea level. If the sea level rises at an increased rate, the tidal basin deepens slightly over time in relation to the rising sea level. At the beginning of this process, the sand retention capacity of the deepened basin gradually increases (Fig. 7). The total quantity of sand required to restore dynamic equilibrium is directly proportional to the rate of RSLR. If the supply of sediment is not sufficient to allow the tidal area to keep pace with RSLR, dynamic equilibrium cannot be regained. In that case, the level of the lagoon will gradually lag behind the rise in sea level, eventually bringing about the area's inundation (Louters and Gerritsen, 1994). The findings of Louters and Gerritsen (1994) were subsequently discussed in the study of Gerritsen and Berentsen (1998), who modelled sediment balance in the wider North Sea Basin for the Holocene SLR, but for a single tidal basin scale. 
Other recent and relevant studies of basin evolution include the work of Defina et al. (2007), who developed a conceptual model for Venice Lagoon, showing the same patterns of evolution described in Louters and Gerritsen (1994). Such studies also include the work of Lopes et al. (2011), who applied the morphodynamic model MORSYS2D to Ria de Aveiro, and described impacts of RSLR on lagoon hydrodynamics that included an increase in the tidal prism at the lagoon mouth of about $28 \%$, as well as an intensification in sediment fluxes, and, consequently, bathymetric changes. More recently, Dissanayake et al. (2012) modelled a typical large inlet/basin system, the Ameland Inlet, over a 110 year study period, and found an existing flood dominance of the system with increasing rates of RSLR, caused by erosion of the ebb-tidal delta and accretion of the basin. Van der Wegen et al. (2013) showed that the intertidal area might disappear under realistic RSLR rates, with the basin shifting from a sediment-exporting system to an importing system, as well as the basin 'drowning' and a considerable reduction in the extent of intertidal areas.

The recent review by Coco et al. (2013) of the morphodynamics of tidal networks discusses tidal drainage accommodation space and how tidal channels increase in both width and depth as a result of RSLR and related changes in the flowing tidal prism. Stefanon et al. (2012) provided similar findings, reporting a linear relationship between the tidal prism and the drainage area of the basin, and showing that a decrease in the tidal prism leads to smaller channel cross-sections and a general retreat of the channels, whereas the opposite effect (network expansion and larger cross-sectional channel areas) occurs when the tidal prism increases.

\subsection{RSLR and salt marsh evolution}

The presence of a marsh platform reduces basin accommodation space as a barrier migrates across the backbarrier region in response to RSLR. Therefore, a good way of predicting the maturity of coastal lagoons is to evaluate salt marsh accumulation rates. Furthermore, salt marsh accumulation rates are also reliable proxies for estimating past RSLR rates (e.g., Edwards, 2007; Cronin, 2012).

Marshes cover extensive areas of estuarine and deltaic environments in mid- to high latitudes and support different vegetation types, and also show different rates of inundation and suspended sediment delivery (e.g., FitzGerald et al., 2006; French, 2006; Cronin, 2012). In addition to their dependence on RSLR, the success of marsh maintenance also depends upon other factors such as sediment supply and tidal range (Reed, 1995). Rising water levels could potentially alter the inundation regime in salt marsh habitats, leading to irreversible

401 Venice Lagoon greatly influenced shifts in the margins of the salt marsh and the meander 402 evolution of tidal channels in the long term, but short-term changes in creek sinuosity were 
403 often also closely related to variations in tidal range. The retreat of marsh margins, the

404 increase in network density, and the decrease in creek sinuosity provided evidence for tidal

405 channel development in a regime of RSLR and an increasing strength and frequency of high

406 tides (Rizzetto and Tosi, 2012).

407 The physical responses of salt marshes to RSLR have been frequently coupled with

408 morphological models (e.g., Schwimmer and Pizzuto, 2000; Mariotti and Fagherazzi, 2010;

409 Coco et al., 2013). Recent studies have aimed to improve understanding of the morphological

410 development of marshes by considering factors such as the rate of RSLR, the depth of

411 inundation, inorganic sediment supply, plant productivity, and the accumulation of organic

412 material (e.g., Fagherazzi and Sun, 2004; D’Alpaos et al., 2005; Kirwan et al., 2008). In these

413 models, morphological changes are based on the balance between erosion (dependent on

414 shear stress criteria), inorganic accretion, and organic production, as found from empirical

415 relationships (Morris et al., 2002). Furthermore, successive versions of the sea level affecting

416 marshes model (SLAMM) have been used to estimate the impacts of SLR along the coasts of

417 the United States (e.g., Titus et al., 1991; Craft et al., 2009; Traill et al., 2011; Glick et al.,

418 2013). Besides numerical modelling, other approaches have been used to determine the

419 response of salt marshes to RSLR. For example, using a lab flume experiment, Stefanon et al.

420 (2012) explored the morphological impact of sea-level fluctuations (both decrease and rise)

421 on a tidal network pattern, and demonstrated rapid network adaptation as a result of varying

422 mean water levels and associated tidal prisms. Simulations of these interactions show that salt

423 marshes are able to keep up with RSLR (e.g., Kirwan et al., 2010).

424 In fact, the published model results show that salt marshes are constantly adjusting

425 towards a new equilibrium (Morris et al., 2002); therefore, the interplay between sediment

426 dynamics and the rate of RSLR has been suggested as being critical for the establishment of

427 the equilibrium intertidal area configuration (Marani et al., 2007). This has lately also led to

428 the idea that salt marshes barely attain equilibrium but rather continuously lag and attempt to

429 readjust to changes in sea level (Kirwan and Murray, 2008). Their ability to rapidly accrete

430 vertically and horizontally under favourable conditions reinforces the notion that natural

431 marshes can quickly respond to external forcing (Friedrichs and Perry, 2001; van Wijnen and

432 Bakker, 2001). Marshes will be under severe stress only if the supply of sediment and the

433 build-up of organic material cannot keep up with rising sea level (e.g., Morris et al., 2002;

434 Nielsen and Nielsen, 2002; Temmerman et al., 2004; French, 2006; Kirwan and Temmerman,

435 2009; Andersen et al., 2011). For instance, the recent expansion of water-logged panes in salt

436 marshes in the northeastern United States has been attributed to tidal flooding associated with

437 accelerated rates of RSLR (Hartig et al., 2002). Sediment supply reduction and increased

438 subsidence rates were partially responsible for the reductions in the extent of marshland in

439 Chesapeake Bay and Venice lagoon marshes (Reed, 1995; Day et al., 1998; Marani et al., 
441 Salt marsh growth and development substantially alters the sedimentary processes

442 occurring in lagoons (Fagherazzi et al., 2012; Coco et al., 2013). Herein, we propose a generic

443 conceptual scheme illustrating salt marsh development with respect to RSLR (Fig. 8). It is

444 assumed that the salt marsh accretion rate is the net product of sediment deposition and

445 physical compaction (Bartholdy et al., 2004). Essentially, RSLR is portrayed as creating

446 accommodation space in which fine-grained sediments can settle (sediment supply rate), so

447 that increases in the rate of RSLR theoretically lead to concomitant changes in the rates of

448 mineral sediment deposition (in agreement with the results of Redfield, 1972); however,

449 under high rates of RSLR, with an insufficient supply of sediment and organic material,

450 inundation of the salt marsh will occur. In contrast, if the rate of sediment supply is much

451 higher than the rate of RSLR, silting-up dominates and the marsh will shift towards a

452 different environment and ecosystem (an infilling lagoon).

453 Assuming a sufficient supply of sediment, and after an initial phase of growth, the

454 SMG (salt marsh growth) rate will tend to attain equilibrium with the rate of RSLR (Fig. 8,

455 central panel), and the salt marsh surface, also referred to as the marsh platform, will be at a

456 level between near mean high tide (Krone, 1987) and just below the highest (astronomical)

457 tide (Allen, 2000). The elevation of the platform relative to sea level determines the total

458 wetland area, inundation frequency and duration, and wetland productivity (Morris et al.,

459 2002).

460 If SMG rates are too low to keep pace with the rate of RSLR (slow growth as result

461 of low silt input), the intertidal area in the lagoon is dominated by inundation, and there is no

462 effective salt marsh development (Fig. 8, upper panel). If the amount of inundation becomes

463 sufficient to stress or kill vegetation, then the marsh substrate begins to break up as peat

464 collapses: salt marshes cannot adapt and may drown, the lower part of the substrate may

465 become eroded (Kirwan et al., 2010; Cronin, 2012), and inner channel networks will expand

466 (Hartig et al., 2002). There is no predefined time lag applying to when the marsh substrate

467 begins to break up (or recover), and future research must seek to estimate the capacity for

468 resilience of these areas. This threshold appears to have already been reached for many of

469 coastal Louisiana's wetlands, owing to a number of anthropogenic and natural factors

470 (Morton et al., 2005). In contrast, if SMG rates are higher than rates of RSLR (rapid growth

471 as result of excessive silt input), the intertidal area becomes sediment saturated and the salt

472 marsh will shift horizontally if there is enough accommodation space (Fig. 8, lower panel).

473 The process leads to a loss of inner-basin area and a continuation of infilling, resulting in salt

474 marsh decay over the long term.

475 The two extreme conditions portrayed above bear negative impacts on the extent of

476 both salt marshes and basins. Determining the clear effects of each of them remains difficult, 
because the effects of RSLR alone cannot be isolated in natural wetlands. Even if we presume that vertical accretion in salt marshes is solely a function of inorganic and organic matter influx and ignore the effects of regional subsidence along coastlines, it is clear that many marshes will not be able to keep up with the projected increase in the rate of SLR forever, which might result in the partial conversion of marshlands to subtidal and unvegetated intertidal areas (Ashton et al., 2007). The ultimate submergence of coastal marshes occurs when there is insufficient elevation to prevent excessive waterlogging of the marsh soil (as observed by Reed (2002) in the Mississippi salt marshes).

Day et al. (1998) compiled information about salt marsh accretion rates, reporting a vertical accretion rate of $0.3-2.3 \mathrm{~cm} \mathrm{yr}^{-1}$ in Venice lagoon as measured over two years. FitzGerald et al. (2006) reported an interval of $0-14 \mathrm{~mm} \mathrm{yr}^{-1}$, with a mean rate of $5.0 \mathrm{~mm}$ $\mathrm{yr}^{-1}$. Pethick (1992) measured accretion rates of $>2.0 \mathrm{~cm}$ over two years in a salt marsh in 489 England, although this was not specifically for a coastal lagoon. Assuming the IPCC's mean estimate of $74 \mathrm{~cm}\left(9 \mathrm{~mm} \mathrm{yr}^{-1}\right)$ of SLR by the end of this century for the RCP8.5 scenario, and a salt marsh average accretion rate of $5.0 \mathrm{~mm} \mathrm{yr}^{-1}$ (assuming the mean rate of FitzGerald et al., 2006), the amount of SMG will be (on average) lower than the amount of RSLR, and intertidal lagoons will be prone to inundation. In a large number of coastal systems worldwide, the accretion will be insufficient to prevent water-logging of marsh soil, leading to plant deterioration. This could be particularly relevant by the end of the twenty-first century, because the overall $74 \mathrm{~cm}$ of SLR includes an acceleration in SLR from the present day until the end of the century. The exceptions would be places with high availability of sediment, where salt marshes can survive under a rate of RSLR in excess of $1 \mathrm{~cm} \mathrm{yr}^{-1}$ (as observed in the Mississippi delta by Reed, 2002).

The adjustment of salt marshes to RSLR also depends on the acceleration of sea-level rise. The experimental results of Kirwan and Temmerman (2009), as illustrated in Figure 9, help to quantify the strength of the lagoon inundation-accretion feedback and the response of marsh accretion rates to step-by-step changes in the rate of RSLR. The results of Kirwan and Temmerman (2009) suggest that regardless of the magnitude of change, a marsh adjusts to a change in the rate of RSLR within about 100 years (returns to equilibrium, Fig. 9). Sediment availability is assumed, and the forecast accretion occurs because a feedback is considered between inundation and suspended sediment concentrations (sediment deposition rates are proportional to inundation depth) that allows marshes to quickly adjust their elevation to a change in the rate of sea-level rise. The long-term behaviour as suggested by the experiments of Kirwan and Temmerman (2009) fits some of the behaviours observed in the Louisiana wetlands (DeLaune et al., 1994), but does not match other response scenarios such as the expansion of drainage networks of tidal creeks in Cape Romain, South Carolina (Hughes et al., 2009). 
Abiotic parameters also control salt marsh responses. Riverine-dominated salt marshes (such as many Gulf Coast and Chesapeake Bay marshes) experience greater sediment accumulation as a result of enhanced input of inorganic sediment compared with marshes, where the major source of inorganic sediment is marine (FitzGerald et al., 2006).

518 Lagoon marshes that do not experience significant fluvial delivery of inorganic sediment may therefore be at greater risk of inundation with rising sea level, as the main source of inorganic sediment to these marshes is the ocean, via tidal inlets. In coastal lagoons and estuaries, an absolute increase in the elevation of the marsh platform in response to rising sea level should cause a landward migration of the marsh (Gardner and Porter 2001), and this may change the areal extent of wetland and consequently total production, depending on local geomorphology and anthropogenic barriers to migration.

\section{Modelling the evolution of coastal lagoons under RSLR scenarios}

Numerical models have proved to be fundamental tools for gaining insights into barrier evolution and resilience, and have evolved significantly in the last 20 years. They have been developed and validated mostly for ocean front beaches and have only rarely been applied to the overall evolution of coastal lagoons. Indeed, there is a lack of model predictors adapted to the study of coastal embayments and lagoons. The following review is therefore focused on morphodynamic models that are commonly used in coastal applications, but which have apparent applicability to coastal lagoons.

Models relating SLR and coastal evolution have been developed for making longterm predictions, and in the last 20 years have experienced huge improvements in complexity, applicability, and reliability. Such models can be split into three main groups: simple shoreline models, behaviour models, and process-based models. These models can be applied at various degrees of dimension. One-dimensional models are ideal for studying, for example, width-average equilibrium profiles; two-dimensional models account for the formation of depth-averaged features (e.g., a channel or shoal); and three-dimensional models additionally account for small-scale hydrodynamic changes in the vertical dimension, that is, due to curvature or density gradients (Hibma, 2004; Lesser et al., 2004).

The older and most widely used sandy shoreline response models include the Bruun

545 2005). Several studies claim to have demonstrated the applicability of the Bruun rule (e.g.,

546 Leatherman et al., 2000; Zhang et al., 2004), and, perhaps because of its elegant simplicity, its use has become commonplace by coastal planners and managers (Pilkey and Cooper, 2004). In the last 10 years, criticisms of the Bruun rule have been many and varied (e.g., Sallenger,

549 2000; Cooper and Pilkey, 2004). Several authors have pointed out that this principle is

550 applicable only to a restricted number of beaches (coasts without net alongshore sediment 
551 transport; Brunel, 2009). Consequently, several modifications to the Bruun rule have been

552 made in attempts to attain greater accuracy in representing the response of the beach profile to

553 SLR (e.g., Komar et al., 1991; FitzGerald et al., 2008; Rosati et al., 2013).

554 During the 1990s, a suite of quantitative morphological behaviour models was

555 developed, namely, the large-scale coastal behaviour (LSCB) models. Behaviour models are

556 used to simulate the large-scale morphological and stratigraphic evolution of coasts that

557 occurs as a result of changes in sea level and in sediment supply (e.g., Cowell et al., 1995;

558 Niedoroda et al., 1995; Stive and de Vriend, 1995). Similar to the way in which shoreline

559 response models use time as a surrogate for processes, the LSCB models utilize geometric

560 cross-shore profile parameters as proxies for processes. As an example, the Integrated

561 Assessment Models (IAMs) appeared at the beginning of the twenty-first century and are used

562 to evaluate the vulnerability of coastal systems to multiple climate change impacts. The

563 ability to achieve a fully integrated assessment of coastal vulnerability, considering dynamic

564 interactions between sectors and/or processes, makes IAMs very useful in supporting policy-

565 and decision-making at various scales. However, given the complex nature of such models,

566 their implementation requires significant expertise. FUND, DIVA (Dynamic interactive

567 assessment model), SimCLIM, and RegIS (Regional Impact Simulator) are examples of IAMs

568 dealing with the valuation and management (in terms of adaptation) of multiple climate

569 change impacts on coastal areas and related ecosystems (see Hinkel, 2005; Holman et al.,

570 2008; Warrick, 2009; Mcleod et al., 2010). For example, FUND is an integrated assessment

571 model with a coastal impact component that includes country-level cost functions for dry land

572 loss, wetland loss, forced migration, and dike construction (Tol, 2007); it works at the sector

573 level, so that economic costs can be estimated for SLR. DIVA is a dedicated coastal impact

574 model employing subnational coastal data (Vafeidis et al., 2008), and considers additional

575 impacts such as coastal flooding and erosion as well as adaptation in terms of protection via

576 dikes and nourishment (Hinkel and Klein, 2009). DIVA assesses coastal flood risk based on

577 the hydrological elevation and extreme water level distributions (Hinkel et al., 2013) and

578 erosion based on a combination of the Bruun rule and a simplified version of the ASMITA

579 (Aggregated Scale Morphological Interaction between Tidal inlet and Adjacent coast) model

580 for tidal basins (Nicholls et al., 2011).

581 In clear contrast to the aforementioned behaviour models are the 2D process-based

582 models and the recent 3D circulation process-based models, which when coupled with

583 sediment transport processes demonstrate success at modelling hydrodynamics and

584 morphology over shorter time scales (Lesser et al., 2004; Roelvink 2006). Process-based

585 models consider changes in the patterns of circulation inside coastal basins (McLeod et al.,

586 2010), portraying different coastline changes and tidal sedimentation scenarios along the

587 same coastal system. Although not specifically developed to deal with climate change 
impacts, these models can be applied to sector analysis (e.g., shoreline change and storm impact simulations) or to the integrated assessment of coastal vulnerability to SLR. The main examples include Delft3D, developed by Deltares (e.g., Lesser et al., 2004; Tung et al., 2009; van der Wegen and Roelvink, 2012), MIKE 2D, and the KUTM (the Kyushu University Tidal Model). Comprehensive morphodynamic modelling systems such as ECOMSed, Mike-21, Delft3D ROMS, and TELEMAC-MASCATE (Hervouet and Bates, 2000; http://www.opentelemac.org) generally include different flow modules (from 1D to 3D), a wave propagation model, and a sand transport model including bed load and suspended load (Villaret et al., 2013; see the example in Fig. 10), which allow integrated modelling of complex coastal systems to be performed at different time scales. Van Dongeren and de Vriend (1994), Stive and Wang (2003), and van Goor et al. (2003) have shown that this type of model has the capacity to predict the decadal-scale morphodynamic development of coasts, including the impact of SLR.

With the development of process-based models, the coastal research community experienced a proliferation of numerical method applications. Although this approach requires a higher level of input data compared with the behaviour models, the output of process-based models provides more detailed information on governing processes (van der Wegen et al., 2013). Filtering methods such as tide lengthening or the use of the so-called morphodynamic factor have been extensively applied to reduce computational costs for longterm applications, but such methods also introduce an additional source of uncertainty (van der Wegen and Roelvink, 2008). Many of the models traditionally used to study coastal processes made, by necessity, critical simplifying assumptions that limit their applicability (Ashton et al., 2007). Oversimplification, limited observations, and unknowable future conditions still limit models' ability to make quantitative reliable predictions.

The existing limitations of process-based models concerning the predictability of morphological variables because of the non-linearity of many coastal systems has recently encouraged the development of 'hybrid models' (featuring elements of both top-down and bottom-up models) with simplified dynamics that are designed to predict qualitative behaviour by including only predominant processes (Karunarathna et al., 2008). Recent experimentation includes the model types proposed by Karunarathna et al. (2008) and

618 Townend (2010) for estuaries and tidal inlets. Bayesian networks have also been applied to or 619 can provide probabilistic predictions of shoreline change rates using readily available data on 620 driving forces (rate of sea level rise, wave height, tidal range) and boundary conditions (e.g., geomorphological setting, coastal slope) (see Gutierrez et al., 2011).

A problem highlighted in all research pertaining to morphodynamic modelling is that

623 of the accuracy and verification of results or predictions arising from the numerical

624 calculations. The nature of modelling for predicting future change means that until the 
625 predicted change takes place, the model cannot be deemed to be ultimately accurate. The use

626 of models to explore and simulate the operation of contemporary processes in natural science

627 can be an important tool if used wisely and while accounting for limitations and the quality of

628 data required for parameterisation (e.g., Roelvink and Reniers, 2012). However, their use as a

629 long-term, large-scale predictive tool is in its infancy and therefore their value is expected to

630 substantially improve in the future.

\section{The economic and social consequences of RSLR for coastal lagoons}

A given rate of SLR can have differential impacts on economic and social systems

634 depending on where the rise occurs and which population groups are affected. Where

635 exposure and vulnerability are high, even non-extreme events can lead to serious

636 consequences (IPCC, 2013; Felsenstein and Lichter, 2014). Thus, the relative burden of

637 coping with the effects of RSLR is more important from a socioeconomic perspective than is

638 the absolute size of the event (Felsenstein and Lichter, 2014). There are no specific studies on

639 human vulnerability to the expected SLR in coastal lagoons (even in AR4 or AR5), only a

640 few case study examples. For instance, in the absence of anthropogenic barriers, a $1 \mathrm{~m}$ rise in

641 sea level would create around $11,000 \mathrm{~km}^{2}$ of new intertidal area in the conterminous United

642 States alone (Morris et al., 2012; Kirwan and Megonigal, 2013).

643 The availability of regional-scale comprehensive vulnerability assessment studies,

644 which are required by local stakeholders for designing adaptation strategies at the local level,

645 is limited (Cooper et al., 2008). Only recently have studies reported human impacts and

646 coastal lagoon management implications arising from RSLR. Cooper et al. (2008) evaluated

647 coastline displacement and its consequences based on the direct inundation of Delaware Bay

648 (New Jersey), and listed the methodologies that may prove useful to policy-makers despite

649 the large uncertainties inherent in the analysis of the local impacts of sea-level change.

650 Carrasco et al. (2012) assessed the inundation of backbarriers and proposed several human

651 adaptation measures, focusing mostly on sandy stretches. Raji et al. (2013) used GIS

652 techniques to assess the number of people at risk from flooding, and constructed a socio-

653 economic vulnerability index according to the distribution of the land uses across physical

654 vulnerability classes. The relatively small number of studies integrating human impacts and

655 morphodynamic evolution induced by RSLR is perhaps because of our need to continue

656 learning how to interpret SLR itself as well as the associated coastal evolution (Ward et al.,

657 2012). Although the study of Cooper and Lemckert (2012) was not exclusively dedicated to

658 coastal lagoons, it highlighted some of the practical considerations that specifically

659 characterize large coastal resort cities. Yoo et al. (2011) developed a methodology for

660 assessing vulnerability to both climate change and RSLR in coastal cities. Other pertinent

661 examples of economic estimates of material losses caused by the consequences of 
662 morphodynamic readjustments to RSLR can be found in Ribbons (1996), Anthoff et al.

663 (2010), Merz et al. (2010), and Le Van Thang et al. (2011), who examined the direct link

664 between poverty and RSLR in the lagoons and coastal areas of Thua Thien province,

665 Vietnam.

666 The small size and dispersed distribution of coastal lagoons along coastlines can lead 667 to their mismanagement. In addition, administrative frontiers often do not facilitate a coherent 668 management of coastal lagoons (Gaertner-Mazouni and De Wit, 2012). The main economic 669 and social approaches used to face RSLR rely fundamentally on the adaptation and mitigation 670 options. Clearly important for the definition of adaptation measures is to better understand the 671 links between barrier systems, lagoon marshes, and tidal basins (Ashton et al., 2007), and 672 human frame, and how these features will evolve during RSLR. According to the United 673 Nations International Strategy for Disaster Reduction (UNISDR, 2009), adaptation is 'the 674 adjustment in natural or human systems in response to actual or expected climatic stimuli or 675 their effects that moderates harm or exploits beneficial opportunities'. Some researchers view society as the adaptive unit; that is, adaptation is the ability of a system to return to functionality. Others perceive the unit of adaptation as being the largest and most inclusive group that makes and implements decisions with respect to exploitation in the habitat (OliverSmith, 2009). In contrast to adaptation, mitigation is the 'lessening or limitation of the adverse impacts of hazards and related disasters, and encompasses engineering techniques and hazard-resistant construction as well as improved Env.al policies and public awareness'

682 (UNISDR, 2009). Mitigation is proactive and increases the resilience of a society; that is,

683 increasing the capacity to absorb the impacts of hazards that exist in its surroundings without 684 major disruption of basic functions. Even with RSLR mitigation measures, coastal adaptation remains essential (Nicholls et al., 2007). The growing populations and economies of the coastal zone reinforce this need. However, the simple implementation of an adaptation measure is not an endpoint; rather, adaptation is an ongoing process requiring the constant prioritisation of risks and opportunities, the implementation of risk-reduction measures, and reviews of their effectiveness. Hence, the performance of any adaptation measure (within the scope of an integrated coastal zone management framework) should be carefully monitored

691 during its implementation to improve its maintenance and other future interventions (UNEP,

692 2010). Only 'no-regret' strategy measures (providing economic and environmental benefits

693 by fostering innovation and economic development) and 'insurance' responses by the

694 insurance industry (dealing with the precautionary principle where RSLR would have large costs) will be appropriate in the next few decades as coastal management actions (Nicholls and Mimura, 1998).

\section{Future challenges}



surrounds its potential impacts, and future challenges include the following. First, the lessons learned about the patterns of variation in RSLR need to be more widely recognised by climate scientists (Woodroffe and Murray-Wallace, 2012) to improve the prediction of sea-level change and to further improve management actions to deal with it. Second, models of both past and future coastal changes must be more aware about the human role at the coast (Ashton et al., 2007), and their improvement, testing, and validation of should be a priority. In general, most studies of nearshore processes have been conducted on long, straight shorelines, and the mechanisms driving shoreline and coastal change along coasts with complicated nearshore and surf zone bathymetry, inlets, headlands, or lagoons are less well understood. Indeed, model uncertainties may be still large and the need for further research on these coastal areas is great. Besides, the morphodynamic variability of coastal features and the relationship of

711 such variability with RSLR is not linear and the problem of nonlinear, multiple-scale 712 dynamics is still far from being solved (e.g., Dastgheib et al., 2008).

Third, the socio-economic drivers, RSLR scenarios, and impacts considered as well as damage and losses valued are all still fragmentary (Yohe et al., 2012). For example, the costs of land loss due to increased coastal inundation, the cost of forced migration due to permanent inundation, and the impacts of RSLR in combination with other drivers on ecosystems have not been assessed at local scales (e.g., Gornitz et al. 2002). The rates of change of coastal lagoon shorelines are also of interest where wetland regeneration is concerned, for the conservation of threatened species (Reed, 1990), for the flood-buffering properties of vegetation (Townend and Pethick, 2002), and in the burgeoning field of carbon sequestration (e.g., Morris et al., 2012; Chmura, 2013). In agreement, the non-market value of ecosystem services must be used to promote the conservation, restoration, and creation of wetlands in coastal lagoons, and to protect adjacent uplands for wetland transgression (Kirwan and Megonigal, 2013).

Although the future magnitude of RSLR impacts can be reduced by mitigation, the long time scales of ocean response mean that it is unclear which coastal impacts are avoided and which impacts are simply delayed. The 'commitment to sea-level rise' (Nicholls et al.,

728 2006; Nicholls and Lowe, 2006) should be 'for life'. Moreover, when efforts to reduce

729 climate-related risks to coastal systems are reactive and standalone, they are less effective

730 than when they are part of an integrated coastal zone management (Nicholls et al., 2007).

731 Integrated coastal zone management is recognized as the most appropriate framework to deal 732 with climate change, SLR, and other current and long-term coastal challenges (Nicholls and 733 Klein, 2005). Proactive adaptation to climate change aims to reduce a system's vulnerability 734 by minimizing risk and/or enhancing the system's resilience. With adaptation planning 735 proliferating as a strategy for managing the risks of climate change to coastal systems, 
736 attention is beginning to shift towards evaluating how effective such planning has been. The

737 precise boundary between what is appropriate at the national and regional levels may be

738 fuzzy, and in many cases regional/local-scale efforts will become more efficient in terms of

739 achieving adaptation than will the adoption of national-scale policies (Nicholls and Minura,

740 1998). To effectively cope with RSLR and its impacts, current policies and economic

741 considerations should be examined, and possible options for changing planning and

742 management activities warranted, so that both society and the natural environment can more

743 effectively adapt to potential acceleration in SLR.

744 To sum up, some topics still need to be explored and detailed in the future:

745 - Downscaling SRL effects from the global level to regional and local levels in order to

746 typify and identify the evolution for each specific coastal lagoon;

747 - Improving the reliability of model scenarios/predictions, accounting for the effect of

$748 \quad$ RSLR jointly with extreme events on the evolution of coastal areas;

749 - Defining ecological losses/shifts and how they interact with morphological shifts,

$750 \quad$ including feedback mechanisms that are not yet understood or modelled;

- Defining how to implement increases or decreases in sediment rate inside lagoons in conceptual and numerical models in a quantified way and including the morphodynamic response of the systems; and

- Evaluating the impacts of RSLR on coastal communities and the effectiveness and efficiency of adaptation interventions.

The present review shows that the level of knowledge regarding the potential severity of the consequences of climate change (and particularly SLR) on coastal zones is still insufficient. Uncertainty increases as we move from the natural subsystem to the human subsystem, with the largest uncertainties concerning their interaction. An understanding of this interaction is critical to gaining a comprehensive understanding of human vulnerability in coastal lagoons and should include the role of institutional adaptation and public participation. Determining what to protect, how to pay for it, and how those choices are made also raises concerns with respect to equity and to social, cultural, and environmental justice that must be

\section{Conclusions}

It should be borne in mind that because of regional differences in SLR, the occurrence

768 of and response to the effects of climate change will not be uniform worldwide. The major

769 sources of uncertainty are the projected mean SRL estimates and how and when RSLR will

770 manifest itself at different scales, and in agreement with the context of local sediment

771 availability. Therefore, the nature of the long-term morphodynamic response of coastal 
lagoons to RSLR will depend on the type of basin and on the availability of external sediment

773 to meet the increasing sediment demand within the system. Coastal lagoons present a

774 complex evolution and a complex response to change. As extensively highlighted, this

775 response is spatially variable owing to variations in sediment supply and salt marsh accretion

776 rates. For instance, if the basin has an abundant and continuous influx of external sediment,

777 then it will be able to maintain its morphology and reach a stable state. In the absence of an

778 adequate supply of external sediment, some of the prominent features (salt marshes and spits)

779 are likely to recede or disappear altogether during the adjustment process, and inundation

780 processes will dominate. The threshold at which features are eroded occurs varies widely, and

781 is largely dependent on changes in erosion and sedimentation. Morphological modelling has

782 been widely used to predict the potential of erosion/accretion at different time scales. In

783 particular, process-based models have been herein considered as important tools for

784 portraying coastline changes and sedimentation scenarios in coastal lagoons in response to

785 different rates of RSLR, but such modelling requires further development and validation.

786 A relatively small number of detailed studies have integrated and quantified human

787 impacts and morphodynamic evolution induced by SLR at coastal lagoons, possibly because

788 we still do not completely understand how to interpret RSLR itself and the associated coastal

789 evolution. Several questions still remain unanswered, including the degree to which the

790 observed changes will be locally important (in each coastal system) from the natural and

791 socio-economic points of view. Although research is required at all scales, an improved

792 understanding at the physiographic unit scale (e.g., coastal lagoons, deltas, and estuaries)

793 would have particular benefits, and could support decisions made regarding adaptation to

794 RSLR and lead to better coastal management actions. Therefore, a local focus on each lagoon

795 system and the determination of its potential evolution over the next decades to a century in

796 response to SLR must be addressed in future research.

\section{Acknowledgments}

799 A.R. Carrasco was supported by Fundação para a Ciência e Tecnologia, grant reference

800 SFRH/BPD/88485/2012. The contribution of Ó. Ferreira was included under the scope of the

801 EU project RiscKit (FP7 Grant Agreement No. 603458).

\section{References}

804 Allen, J. R. L., 2000. Morphodynamics of Holocene salt marshes: A review sketch from the Atlantic and southern North Sea coasts of Europe. Quat. Sci. Rev., 19, 1155-1231 291-296. 
Andersen, T.J., Svinth, S., Pejrup, M., 2011. Temporal variation of accumulation rates on a natural salt marsh in the 20th century - The impact of sea level rise and increased inundation frequency. Marine Geol., 279, 178-187.

Andrade, C., Freitas, M., Moreno, J., Craveiro, S., 2004. Stratigraphical evidence of Late Holocene barrier breaching and extreme storms in lagoonal sediments of Ria Formosa, Algarve, Portugal. Marine Geol., 210, 339-362.

Anthoff, A., Nicholls, R.J., Tol, R.S.J., Vafeidis, A.T., 2006. Global and regional exposure to large rises in sea-level: a sensitivity analysis. Review on the Economics of Climate Change, working paper 96.

Anthoff, D., Nicholls, R.J., Tol, R.J., 2010. The economic impact of substantial sea-level rise. Mitigation and Adaptation Strategies for Global Change, 10, 321-335.

Ashton, A.D., Donnelly, J.P., Evans, R.L., 2007. A Discussion of the Potential Impacts of Climate Change on the Shorelines of the Northeastern USA. Northeast Climate Impacts Assessment, Union of Concerned Scientists, p. 25.

Barnes, R.S.K. (1980). Coastal lagoons; the natural history of a neglected habitat. 106 pp. Cambridge University Press, Cambridge .

Bartholdy J., Christiansen C., et al., 2004, Long term variations in backbarrier salt marsh deposition on the Skallingen peninsula - the Danish Wadden Sea, Marine Geol., 203, $1-21$

Boyd, R., Darlymple, R., Zaitin, B.A., 1992. Classification of clastic coastal depositional Env.s. Sediment. Geol., 80, 139-150.

Carrasco, A.R., Ferreira, Ó., Matias A. and Freire, P., 2012. Flood hazard assessment and management of fetch-limited coastal Env.s. Ocean \& Coast. Manag., 65, 15-25.

Carter, R.W.G., Woodroffe, C.D., 1994. Coastal evolution: late Quaternary shoreline morphodynamic. Cambridge University Press Cambridge.

Cazenava, A., Llovel, W., 2009. Contemporary Sea Level Rise. Annu. Rev. Marine Sci., 2, $145-173$.

CCSP, 2009: Coastal Sensitivity to Sea-Level Rise: A Focus on the Mid-Atlantic Region. A report by the U.S. Climate Change Science Program and the Subcommittee on Global Change Research. [James G. Titus (Coordinating Lead Author), K. Eric Anderson, Donald R. Cahoon, Dean B. Gesch, Stephen K. Gill, Benjamin T. Gutierrez, E. Robert Thieler, and S. Jeffress Williams (Lead Authors)]. U.S. Environmental Protection Agency, Washington D.C., USA, 320 pp.

Chmura, G.L., 2013. What do we need to assess the sustainability of the tidal salt marsh carbon sink? Ocean \& Coast. Manag., 83, 25-31

Church, J.A., White, N.J., 2006. A 20th century acceleration in global sea-level rise. Geophys. Res. Lett. 33, L01602. 
846

Church, J.A., White, N.L., 2011. Sea-Level Rise from the Late 19th to the Early 21st Century. Surv. Geophys., 32, 585-602.

Chust, G., Borja, A., Liria, P., Galparsoro, I., Marcos, M., Caballero, A., Castro, R., 2009. Human impacts overwhelm the effects of sea-level rise on Basque coastal habitats ( $\mathrm{N}$ Spain) between 1954 and 2004. Estuar. Coast. and Shelf Sci. 84, 453-462.

Coco, G., Z. Zhoua, B. vanMaanenb, M. Olabarrieta, R. Tinocoa and I. Townend (2013). Morphodynamics of tidal networks: Advances and challenges. Marine Geol., 346 116.

Cooper, J.A.G., 2004. Mesoscale geomorphic change on low energy barrier islands in Chesapeake Bay, U.S.A. Geomorphol., 199, 82-94.

Cooper , J.A.G., Lemckert, C., 2012. Extreme sea-level rise and adaptation options for coastal resort cities: A qualitative assessment from the Gold Coast, Australia. Ocean \& Coast. Manag., 64, 1-14.

Cooper, J.A.G., Pilkey, O.H., 2004. Sea-level rise and shoreline retreat: time to abandon the Bruun Rule. Glob. and Planet. Chang., 43, 157-171.

Cooper, M.J.P., Beevers, M.D., Oppenheimer, M., 2008. The potential impacts of sea level rise on the coastal region of New Jersey, USA. Climatic Chang., 90, 475-492.

Cowell, P.J. and Thom, B.G., 1994. Morphodynamics of coastal evolution. In: Carter, R.W.G. and Woodroffe, C.D. (eds), Coastal Evolution: Late Quaternary shoreline morphodynamics, Cambridge: Cambridge University Press, 33-86.

Cowell, P.j., Roy, P.S., Jones, R.A., 1995. Simulation of large-scale coastal change using a morphological behaviour model. Marine Geol., 126, 45-61.

Craft, C., Clough, J., Ehman, J., Joye, S., Park, R., Pennings, S., Guo, H., Machmuller, M., 2009. Forecasting the effects of accelerated sea-level rise on tidal marsh ecosystem services. Front. in Ecol. and the Env., 72, 73-78.

Cronin, T.M., 2012. Rapid sea-level rise. Quat. Sci. Rev., 56, 11-30.

D’Alpaos, A., Lanzoni, S., Marani, M., Fagherazzi, S., Rinaldo, A., 2005. Tidal network ontogeny: channel initiation and early development. J. of Geophys. Res., 110, F02001.

Dastgheib, A., Roelvink, J.A., Wang, Z.B., 2008. Long-term process-based morphological modeling of the Marsdiep Tidal Basin. Marine Geol., 256, 90-100.

Davidson-Arnott, R.G.D., 2005. Conceptual Model of the Effects of Sea Level Rise on Sandy Coasts. J. of Coast. Res., 21, 1166-1172.

Day, J.W.J., Rismondo, A., Scarton, F., Are, D., Cecconi, G., 1998. Relative sea level rise and Venice lagoon wetlands. J. of Coast. Conserv., 4, 27-34. 
de Vriend, H.J., Capobianco, M., Chester, T., de Swart, H.E., Latteux, B., Stive, M.J.F., 1993. Approaches to long-term modelling of coastal morphology: a review. Coast. Eng., 21, 225-269.

DeLaune, R. D., J. A. Nyman, and W. H. Patrick Jr. (1994), Peat collapse, ponding and wetland loss in a rapidly submerging coastal marsh, J. of Coast. Res., 10, 1021- 1030.

Defina, A., Carniello, L., Fagherazzi, S., D’Alpaos, L., 2007. Self-organization of shallow basins in tidal flats and salt marshes, J. of Geophys. Res., 112, F03001.

Dissanayake, D.M.P.K., Ranasinghe, R., Roelvink, J.A., 2012. The morphological response of large tidal inlet/basin systems to relative sea level rise. Climate Chang., 113, 253276.

Dissanayake, D.M.P.K., Roelvink, J.A., van der Wegen, M., 2009. Modelled channel patterns in a schematized tidal inlet. Coast. Eng., 56, 1069-1083.

Dronkers, J., 1998. Morphodynamics of the Dutch Delta, in: Dronkers J, S.M. (Ed.), Physics of Estuaries and Coastal Seas, Balkema, Rotterdam, The Netherlands, pp. 297-304.

Dubois, R., 1992. A re-evaluation of Bruun's rule supporting evidence. J. of Coast. Res., 8, $618-628$.

Edwards, R. J. (2007). Low energy coasts sedimentary indicators. Sea level studies, Elsevier: 2994-3006.

Felsenstein, D., Lichter, M., 2014. Social and economic vulnerability of coastal communities to sea-level rise and extreme flooding. Nat. Hazards, 71, 463-491.

Ferla, M., Cordella, M., Michielli, L., Rusconi, A., 2007. Long-term variations on sea level and tidal regime in the lagoon of Venice. Estuar. and Coast. Shelf Sci., 75, 214-222.

FitzGerald, D.M., Penland, S., Nummedal, D., 1984. Control of barrier island shape by inlet sediment bypassing. Marine Geol., 60, 355-376.

911 FitzGerald, D.M., Buynevich, I.V., Argow, B., 2006. Model of tidal inler and barrier island dynamics in a regime of accelerated sea level rise, International Coastal Sympusium.

914 FitzGerald, D.M., Fenster, M.S., Argow, B.A., Buynevich, I.V., 2008. Coastal impacts due to sea-level rise, Annu. Rev. of Earth and Planet. Sci., 602-647. 
916

917

918

919

920

921

922

923

924

925

926

927

928

929

930

931

932

933

934

935

936

937

938

939

940

941

942

943

944

945

946

947

948

French, J., 2006. Tidal marsh sedimentation and resilience to environmental change: exploratory modelling of tidal, sea-level and sediment supply forcing in predominantly allochthonous systems. Marine Geol., 235, 119-136.

Friedrichs, C.T., Aubrey, D.G., Speer, P.E., 1990. Impacts of relative sea-level rise on evolution of shallow estuaries. Coastal and Estuarine Studies 38, 105-122.

Friedrichs, C.T., Perry, J.E., 2001. Tidal Salt Marsh Morphodynamics: A Synthesis. J. of Coast. Res., SI 27, 7-37.

Frihy, O.E., El-Sayed, M.K., 2013. Vulnerability risk assessment and adaptation to climate change induced sea level rise along the Mediterraneancoast of Egypt. Mitigation Adaption Strategy Glob. Chang., 18, 1215-1237.

Ganju, N.K., Schoellhamer, D.H., 2010. Decadal-Timescale Estuarine Geomorphic Change Under Future Scenarios of Climate and Sediment Supply. Estuar. and Coast., 33, 1529.

Gaertner-Mazouni, N., De Wit, R., 2012. Exploring new issues for coastal lagoons monitoring and management, Estuar., Coast. and Shelf Sci., 114, 1-6.

Gehrels, W.R., Horton, B.P., Kemp, A.C., Sivan, D., 2011. Two Millennia of Sea Level data: the key to predicting change. Eos, Transactions, American Geophys. Union 92, 289 290.

Gerritsen, H., Berentsen, C.W.J., 1998. A modelling study of tidally induced equilibrium sand balances in the North Sea during the Holocene. Continental Shelf Res. 18, 151-200.

Gillanders, B.M., Travis, A.F., Elsdon, S., Halliday, I.A., Jenkins, G.P., Robins, J.B., Valesini, F.J., 2011. Potential effects of climate change on Australian estuaries and fish utilising estuaries: a review. Marine and Freshw. Res., 62, 1115-1131.

Glick, P., Clough, J., Polaczyk, A., Couvillion, B., Nunley, B., 2013. Potential Effects of SeaLevel Rise on Coastal Wetlands in Southeastern Louisiana. J. of Coast. Res., SI 63, 211-233.

Gutierrez, B.T., Plant, N.G., Thieler, E.R., 2011. A Bayesian network to predict coastal vulnerability to sea level rise. J. of Geophys. Res. 116.

Gornitz, V.M., Couch, S., Hartig, E.K., 2002, 'Impacts of Sea Level Rise in the New York City Metropolitan Area', Glob. and Planet. Chang., 3, 61-88.

Hartig, E.K., Gornitz, V., Kolker, A., Mushacke, F., Fallon, D., 2002. Antropogenic and climate-change impacts on salt marshes of Jamaica Bay, New Yok City. Wetlands, 22, 71-89.

Hervouet, J.M., Bates, P., 2000. The TELEMAC modelling system special issue, Hydrol. Processes, 14, 2207-2208

Hibma, A., Stive, M.J.F., Wang, Z.B., 2004. Estuarine morphodynamics. Coast. Eng. 51, $765-778$. 
Hinkel, J., 2005. DIVA: an iterative method for building modular integrated models. Adv. in Geo Sci. 4.

Hinkel, J., D.P. van Vuuren, R.J. Nicholls, and R.J.T. Klein, 2013: The effects of mitigation and adaptation on coastal impacts in the 21 st century. Climatic Chang., 117, 17, 783794.

Hinkel, J. and R.J.T. Klein, 2009: The DINAS-COAST project: Developing a tool for the dynamic and interactive assessment of coastal vulnerability. Glob. Env. Chang., 19(3), 384-395.

Holman, I.P., Rounsevell, M.D.A., Cojacaru, G., Shackley, S., McLachlan, C., Audsley, E., Berry , P.M., Fontaine, C., Harrison, P.A., Henriques, C., Mokrech, M., Nicholls, R.J., Pearn, K.R., Richards, J.A., 2008. The concepts and development of a participatory regional integrated assessment tool. Climate Chang., 90, 5-30.

Horton, B.P., Rahmstorf, S., Engelhart, S.E., Kemp, A.C., 2014. Expert assessment of sealevel rise by $\mathrm{AD} 2100$ and AD 2300. Quat. Sci. Rev., 84, 1-6.

Hughes, Z.J., FitzGerald, D.M., Wilson, C.A., Pennings, S.C., Wieski_K., Mahadevan, A., 2009. Rapid headward erosion of marsh creeks in response to relative sea level rise. Geophys. Res. Lett., 36. L03602

Hunter, J., 2010. Estimating sea-level extremes under conditions of uncertain sea-level rise. Climate Chang., 99, 331-350.

Hunter, J., 2012. A simple technique for estimating an allowance for uncertain sea-level rise. Climatic Chang., 113, 239-252.

Hunther, J., 2010. Estimating Sea-Level Extremes Under Conditions of Uncertain Sea-Level Rise. Climate Chang., 99, 331-350.

IPCC, 2001. Climate Change 2001: Impacts, Adaptation, and Vulnerability. Contribution of Working Group II to the Third Assessment Report of the Intergovernmental Panel on Climate Change. Cambridge: Cambridge University Press.

IPCC, 2007: Climate Change 2007: The Physical Science Basis. Contribution of Working Group I to the Fourth Assessment Report of the Intergovernmental Panel on Climate Change [Solomon, S., D. Qin, M. Manning, Z. Chen, M. Marquis, K.B. Averyt, M. Tignor and H.L. Miller (eds.)]. Cambridge University Press, Cambridge, United Kingdom and New York, NY, USA, 996 pp.

IPCC, 2013: Climate Change 2013: The Physical Science Basis. Contribution of Working Group I to the Fifth Assessment Report of the Intergovernmental Panel on Climate Change [Stocker, T.F., D. Qin, G.-K. Plattner, M. Tignor, S.K. Allen, J. Boschung, A. Nauels, Y. Xia, V. Bex and P.M. Midgley (eds.)]. Cambridge University Press, Cambridge, United Kingdom and New York, NY, USA, 1535 pp. 
IPCC, 2014: Climate Change 2014: Mitigation of Climate Change. Contribution of Working Group III to the Fifth Assessment Report of the Intergovernmental Panel on Climate Change [Edenhofer, O., R. Pichs-Madruga, Y. Sokona, E. Farahani, S. Kadner, K. Seyboth, A. Adler, I. Baum, S. Brunner, P. Eickemeier, B. Kriemann, J. Savolainen, S. Schlömer, C. von Stechow, T. Zwickel and J.C. Minx (eds.)]. Cambridge University Press, Cambridge, United Kingdom and New York, NY, USA.

Karunarathna, H., Reeve, D., Spivack, M., 2008. Long-term morphodynamic evolution of estuaries: An inverse problem. Estuar. Coastal and Shelf Sci., 77, 385-395.

Kirwan, M.L., Murray, A.B., 2008. Ecological and morphological response of brackish tidal marshland to the next century of sea level rise: Westham Island, British Columbia. Glob. and Planet. Chang., 60, 471-486.

Kirwan, M.L., Murray, B., Boyd, W.S., 2008. Temporary vegetation disturbance as an explanation for permanent loss of tidal wetlands. J. of Geophys. Res., 35, L05403.

Kirwan, M., Temmerman, S., 2009. Coastal marsh response to historical and future sea-level acceleration. Quat. Sci. Rev. 28, 1801-1808.

Kirwan, M.L., Guntenspergen, G.R., D’Alpaos, A., Morris, J.T., Mudd, S.M., Temmerman, S., 2010. Limits on the adaptability of coastal marshes to rising sea level. Geophys. Res. Lett. 37, L23401.

Kirwan, M.L., Murray, A.B., Donnelly, J.P., and Corbett, D.R., 2011. Rapid wetland expansion during European settlement and its implication for marsh survival under modern sediment delivery rates. Geol., 39, 507-510.

Komar PD, Lanfredi N, Baba M, Dean RG, Dyer K, et al. 1991. The response of beaches to sea-level changes - a review of predictive models. J. of Coast. Res., 7, 895- 921.

Le Van Thang, Nguyen Huy Anh, Nguyen Trịnh Minh Anh (2011). Climate change and poverty in lagoon and coastal area of Thua Thien Hue province. Third scientific conference in EIA and SEA. Impact of climate change. Proceedings. Hue, 26/8/2011. Page 104-112.

Leatherman, S.P., Zhang, K., Douglas, B.C., 2000. Sea level rise shown to drive coastal erosion. EOS, Transactions of the American Geophys. Union 81, 55-57.

Lesser, G.R., Roelvink, J.A., van Kester, J.A.T.M., Stelling, G.S., 2004. Development and validation of a three-dimensional morphological model. Coast. Eng., 51, 883-915.

List, J.H., Sallenger, A.H., Hansen, M.E., Jaffe, B.E., 1997. Accelerated relative sea-level rise and rapid coastal erosion: testing a causal relationship for the Louisiana barrier islands. Marine Geol., 140, 347-365.

Lopes, C.L., Silva, P.A., Dias, J.M., Rocha A., Picado A., Plecha S., Fortunato A.B., 2011. Local sea level change scenarios for the end of the 21 st century and potential physical impacts in the lower Ria de Aveiro (Portugal). Cont. Shelf Res., 31, 1515-1526. 
Louters, T., Gerritsen, F., 1994. The Riddle of the Sands: A Tidal System's Answer to a Rising Sea Level. Rijkswaterstaat, The Hague, The Netherlands, p. 69.

Marani, M., D’Alpaos, A., Lanzoni, S., Carniello, L., Rinaldo, A., 2007. Biologicallycontrolled multiple equilibria of tidal landforms and the fate of the Venice lagoon. Geophys. Res. Lett., 34, L11402.

Mariotti, G., Fagherazzi, S., 2010. A numerical model for the coupled long-term evolution of salt marshes and tidal flats. J. of Geophys. Res., 115, F01004.

Martin, L., Dominguez, J.M.L., 1994. Geological History of Coastal Lagoons, in: Kjerfve, B. (Ed.), Coastal Lagoon Processes. Elsevier Sci. Publishers, pp. 41-68.

Masetti, R., Fagherazzi, S., Montanari, A., 2008. Application of a barrier island translation model to the millennial-scale evolution of Sand Key, Florida. Cont. Shelf Res., 28, 1116-1126.

Mcleod, E., Poulter, B., Hinkel, J., Reyes, E., Salm, R., 2010. Sea-level rise impact models and environmental conservation: A review of models and their applications. Ocean \& Coast. Manag., 507-517.

Merz, B., Kreibich, H., Schwarze, R., Thieken, A., 2010. Assessment of economic flood damage. Natural Hazards Earth System Sci., 10, 1679-1724.

Morris, J.T., Sundareshwar, P.V., Nietch, C.T., Kjerfve, B., Cahoon, D.R., 2002. Responses of coastal wetlands to rising sea level. Ecology 83.

Morris JT, Edwards J, Crooks S, Reyes E. 2012. Assessment of Carbon Sequestration Potential in Coastal Wetlands. Recarbonization of the Bioshpere: Ecosystem and Global Carbon Cycle, 517-531.

Morton, R.A., Miller, T., Moore, L., 2005. Historical shoreline changes along the US Gulf of Mexico: a summary of recent shoreline comparisons and analyses. J. of Coast. Res., 21, 704-709.

Moore, L. J., List, J. H., Williams, S. J. and Stolper, D. 2010. Complexities in barrier island response to sea level rise: Insights from numerical model experiments, North Carolina Outer Banks, J. of Geophys. Res.-Earth Surface, 115,

Navrotskaya, S.E., Chubarenko, B.V., 2013. Trends in the Variation of the Sea Level in the Lagoons of the Southeastern Baltic. Marine Phys., 53, 13-23.

Nicholson, J., Broker, I., Roelvink, J.A., Price, D., Tanguy, J.M., Moreno, L., 1997. Intercomparison of coastal area morphodynamic models. Coast. Eng., 31, 97-123.

Nicholls, R.J., Mimura, N., 1998. Regional issues raised by sea-level rise and their policy implications. Climate Res., 11, 5-18.

Nicholls, R.J., Klein, R.J.T., 2005. Climate change and coastal management on Europe's coast, in: Vermaat, J., Bouwer, L., Turner, K., Salomons, W. (Eds.), Managing European Coasts: Past, Present and Future. Springer, Germany, pp. 199-226. 
1063

1064

1065

1066

1067

1068

1069

1070

1071

1072

1073

1074

1075

1076

1077

1078

1079

1080

1081

1082

1083

1084

1085

1086

1087

1088

1089

1090

1091

1092

1093

1094

1095

1096

1097

1098

1099

Nicholls, R.J., Tol, R.S.J., 2006. Impacts and response to sea-level rise: a global analysis of the SRES scenarios over the twenty-first century. Philophical Transactions of the Royal Society, 364, 1073-1085.

Nicholls, R.J., S.E. Hanson, J. Lowe, D.A. Vaughan, T. Lenton, A.

Ganopolski, Tol, R.S.J., A.T. Vafeidis, 2006. Metrics for Assessing the Economic Benefits of Climate Change Policies: Sea Level Rise. Report to the OECD.

ENV/EPOC/GSP(2006)3/FINAL. Organisation for Economic Co-operation and Development (OECD). 128 pp.

Nicholls, R.J., Wong, P.P., Burkett, V.R., Codignotto, J.O., Hay, J.E., McLean, R.F., Ragoonaden, S., Woodroffe, C.D., 2007. Coastal systems and low-lying areas, in: M.L. Parry, Canziani, O.F., Palutikof, J.P., van der Linden, P.J., Hanson, C.E. (Eds.), Climate Change 2007: Impacts, Adaptation and Vulnerability. Contribution of Working Group II to the Fourth Assessment Report of the Intergovernmental Panel on Climate Change,. Cambridge University Press, Cambridge, UK, pp. 315-356.

Nicholls, R.J., Marinova, N., Lowe, J.A., Brown, S., Vellinga, P., Gusmão, D., Hinkel, J., Tol, R.S.J., 2011. Sea-level rise and its posible impacts given a 'beyond $4^{\circ} \mathrm{C}$ world' in the twenty-first century. Philosophical tranasctions of the Royal Society, 369, 161168.

Nicholls, R.J., Hanson, S.E., Lowe, J.A., Warrick, R.A., Lu, X., Long, A.J., 2014. Sea-level scenarios for evaluating coastal impacts. Advanced Rev., 5, 129-150.

Niedoroda, A.W., Reed, C.W., Swift, D.J.P., Arato, H., Hoyanagi, K., 1995. Modeling shorenormal large-scale coastal evolution. Marine Geol., 126, 181-199.

Nielsen, N., Nielsen, J., 2002. Vertical Growth of a Young Back Barrier Salt Marsh, Skallingen, SW Denmark. J. of Coast. Res., 18, 287-229.

Oliver-Smith, A., 2009. Sea Level Rise and the Vulnerability of Coastal Peoples. Responding to the Local Challenges of Global Climate Change in the 21 st Century. InterSecTions No. 7. UNU-EHS. Bonn.

Orford, J.D., Pethick, J., 2006. Challenging assumptions of future coastal habitat development around the UK. Earth Surf. Process. and Landf., 31, 1625-1642.

Pfeffer, W.T., 2011. Land ice and sea level rise: A thirty-year perspective. Oceanogr. 24, 94 111.

Pilkey, O., Cooper, J., Lewis, D., 2009. Global distribution and geomorphology of fetchlimited barrier islands. J. of Coast. Res., 25, 819-837.

Pilkey, O.H., Cooper, J.A.G., 2004. Society and Sea Level Rise. Sci. 303, 1781-1782.

Raji, O., Niazi, S., Snoussi, M., Dezileau, L., Khouakhi, A., 2013. Vulnerability assessment of a lagoon to sea level rise and storm events: Nador lagoon (NE Morocco). J. of Coast. Res., 802-807. 
1100

Ranasinghe, R., Duong, T.M., Uhlenbrook, S., Roelvink, D., Stive, M., 2012. Climate-change impact assessment for inlet-interrupted coastlines. Nature Climate Change 3.

Reed, D.J., 1995. The response of coastal marshes to sea-level rise: survival or submergence? Earth Surf. and Landf., 20, 39-48.

Reed, D., 2002. Sea-level rise and marsh sustainability: geological and ecological factors in the Mississipi delta plain. Geomorphol., 48, 233-243.

Ribbons, S., 1996. Flood damage, flood standard an economics risk...Just one piece of the puzzle!, Risk Management seminar, p. 13.

Redfield, A.C., 1965. Ontogeny of a salt marsh estuary. Sci., 147, 50-55.

Redfield, A. C., 1972. Development of a New England salt marsh, Ecol.Monogr, 42(2), 201237, doi:10.2307/1942263.

Riggs, S. R., Cleary, W.J. and Snyder, S. W. 1995. Influence of inherited geological framework on barrier shoreface morphology and dynamics, Marine Geol., 126, 213234.

Rizzetto, F., Tosi, L., 2012. Rapid response of tidal channel networks to sea-level variations (Venice Lagoon, Italy). Glob. and Planet. Change, 92-93, 191-197.

Rosati, J.D., Dean, R.G., Walton, T.L., 2013. The modified Bruun Rule extended for landward transport. Marine Geol., 340, 71-81.

Roelvink, J.A., 2006. Coastal morphodynamic evolution techniques. Coast. Eng., 53, 277287.

Roelvink, D., Reniers A., 2012. A Guide to Modeling Coastal Morphology, Advances in Coast. and Ocean Eng., World Scientific Publishing Company, Sinagore, 274pp.

Roy, P.S., Williams, R.J., Jones, A.R., Yassin, I., Gibbs, P.J., Coaters, B., West, R.J., Scanes, P.R., Hudson, J.P., Nichol, S., 2001. Structure and function of south-east Australian estuaries. Estuar. Coast. and Shelf Sci., 53, 351-384.

Sallenger, A.H., 2000. Storm impact scale for barrier islands. J. of Coast. Res., 16, 890-895.

Schwimmer, R.A., Pizzuto, J.E., 2000. A model for the evolution of marsh shorelines. J. of Sediment. Res., 70, 1026-1035.

Slangen, A.B.A., Katsman, C.A., Van de Wal, R.S.W., Vermeersen, L.L.A., Riva, R.E.M., 2012. Towards regional projections of twenty-first century sea-level change based on IPCC SRES scenarios, Climate Dyn., 38 (5-6), 1191-1209.

Sloss, C.R., Jones, B.G., McClennen, C., de Carli, J., Price, D.M., 2006. The geomorphological evolution of a wavedominated barrier estuary: Burrill Lake, New South Wales, Australia. Sediment. Geol., 187, 229-249.

Smith, N.P., 2001. Seasonal-scale transport patterns in a multi-inlet coastal lagoon. Estuar., Coast. and Shelf Sci., 52, 15-28. 
Stefanon, L., Carniello, L., D’Alpaos, A., Rinaldo, A., 2012. Signatures of sea level changes on tidal geomorphology: experiments on network incision and retreat. Geophys. Res. Lett., 39, L12402.

Stive, M.J.F., de Vriend, H.J., 1995. Modelling shoreface profile evolution. Marine Geol., $126,235-248$.

Stive, M.J.F. and Wang, Z.B., 2003. Morphodynamic modelling of tidal basins and coastal inlets. Ch 13 in: Advances in Coast. Modeling, ed. By C. Lakhan, Elsevier, pp 367392.

Storms, J., G. Weltje, and J. Van Dijke, 2002. Process-response modeling of wave-dominated coastal systems: simulating evolution and stratigraphy on geological timescales, J. Sediment. Res., 72, 226-239.

Temmerman, S., Goversa, G., Wartelb, S., Meir, P., 2004. Modelling estuarine variations in tidal marsh sedimentation: response to changing sea level and suspended sediment concentrations. Marine Geol., 212, 1-19.

Titus, J.G., Park, R.A., Leatherman, S.P., Weggel, J.R., Greene, M.S., Mausel, P.W., Trehan, M.S., Brown, S., Grant, C., Yohe, G.W., 1991. Greenhouse effect and sea level rise: The cost of holding back the sea. Coast. Manag., 19, 171-204.

Tol, R.S.J., 2007. The double trade-off between adaptation and mitigation for sea level rise: an application of FUND. Mitigation Adaptation Strategies Global Change, 12, 741753.

Toldo, E.E., Dillenburg, S.R., Corrêa, I.C.S., Almeida, L.E.S.B., 2000. Holocene Sedimentation in Lagoa dos Patos Lagoon, Rio Grande do Sul, Brazil. J. of Coast. Res., 16, 816-822.

Townend, I., 2010. An exploration of equilibrium in Venice Lagoon using an idealised form model. Continent. Shelf Res., 30, 984-999.

Traill, L.W., Perhans, K., Lovelock, C.E., Prohaska, A., McFallan, S., Rhodes, J.R., Wilson, K.A., 2011. Managing for change: wetland transitions under sea-level rise and outcomes for threatened species. Biodiversity Res., 17, 1225-1233.

Troiani, B.T., Simms, A.R., Dellapenna, T., Piper, E., Yokoyama, Y., 2011. The importance of sea-level and climate change, including changing wind energy, on the evolution of a coastal estuary: Copano Bay, Texas. Marine Geol., 280, 1-19.

Tung, T.T., Walstra, D.R., van de Graaff, J., Stive, M.J.F., 2009. Morphological Modeling of Tidal Inlet Migration and Closure. J. of Coast. Res., 2, SI56, 1080-1084.

United Nations Environmental Programme (UNEP), 2010. Technologies for Climate Change Adaptation - Coastal Erosion and Flooding, Denmark, UNEP-Riso, 149pp.

UNISDR, 2009. Terminology on Disaster Risk Reduction, UN, Geneva, Switzerland, 30 p. 
Vafeidis, A.T., Nicholls, R.J., McFadden, L., Tol, R.S.J., Hinkel, J., Spencer, T., Grashoff, P.S., Boot, G., Klein, R.J.T., 2008. A new global coastal database for impact and vulnerability analysis to Sea-Level Rise. J. of Coast. Res., 24(4), 917-924.

van der Wegen, M., 2013. Numerical modeling of the impact of sea level rise on tidal basin morphodynamics. J. of Geophys. Res.: Earth Surf., 118, 2, 447-460,

van der Wegen, M., Roelvink, J.A., 2008. Long-term morphodynamic evolution of a tidal embayment using a two-dimensional, process-based model. J. of Geophys. Res., 113, C03016.

van der Wegen, M., Roelvink, J.A., 2012. Reproduction of estuarine bathymetry by means of a process-based model: Western Scheldt case study, the Netherlands. Geomorphol., $179,152-167$.

van Dongeren, A.R., de Vriend, H.J., 1994. A model of morphological behaviour of tidal basins. Coast. Eng., 22, 287-310.

van Goor, M.A., Zitman, T.J., Wang, Z.B., Stive, M.J.F., 2003. Impact of sea-level rise on the morphological equilibrium state of tidal inlets. Marine Geol., 202, 211-227.

van Wijnen, H.J., Bakker, J.P., 2001. Long-term Surface Elevation Change in Salt Marshes: a Prediction of Marsh Response to Future Sea-Level Rise. Estuar., Coast. and Shelf Sci., 52, 381-390.

Villaret, C., Hervouet, J., Kopmann, R., Merkel, U., Davies, A.G., 2013. Morphodynamic modeling using the Telemac finite-element system. Comput. \& Geosci., 53, 105-113.

Walters, D., Moore, L. J., Vincent, O. D., Fagherazzi, S., Mariotti, G., 2014. Interactions between barrier islands and backbarrier marshes affect island system response to sea level rise: Insights from a coupled model. J. of Geophys. Res.: Earth Surf., 118, 3, $1908-1920$

Ward, S.L., Green, J.A.M., Pelling, H.E., 2012. Tides, sea-level rise and tidal power extraction on the European shelf. Ocean Dyn., 62, 1153-1167.

Warrick, R.A., 2009. Using SimCLIM for modelling the impacts of climate extremes in a changing climate: a preliminary case study of household water harvesting in Southeast Queensland, 18th World IMACS / MODSIM Congress, Cairns, Australia pp. 2583-2589.

Watson, P.J., 2011. Is there evidence yet of acceleration in mean sea level rise around mainland Australia? J. of Coast. Res., 27, 368-377.

Willis, J.K., Chambers, D.P., Kuo, C.Y., Shum, C.K., 2010. Global sea level rise: Recent progress and challenges for the decade to come. Oceanogr., 23, 26-35.

Wolanski, E., Chappell, J., 1996. Response of TRopical Australian estuaries to a sea level rise. J. of Marine Systems, 7, 267-279. 
1208 Wolinsky, M.A. and Murray, A.B., 2009. A unifying framework for shoreline migration, 2: 1209 application to wave-dominated coasts, J. of Geophys. Res., 144(F1), F01009.

1210 Woodroffe, C.D., Murray-Wallace, C.V., 2012. Sea-level rise and coastal change: the pat as a 1211 guide to the future. Quat. Sci. Rev., 54, 4-11.

1212 Yohe G, Tol RSJ. Indicators for social and economic coping capacity: Moving toward a 1213 working definition of adaptive capacity. Global Env. Change, 2002, 12 (1), 25-40.

1214 Yoo, G., Hwang, J.H., Choi, C., 2011. Development and application of a methodology for vulnerability assessment of climate change in coastal cities. Ocean \& Coast. Manag., $54,524-534$.

Zhang, K., Douglas, B., Leatherman, S.P., 2004. Global warming and coastal erosion. Climate Change, 64, 41-58.

1219

1220 


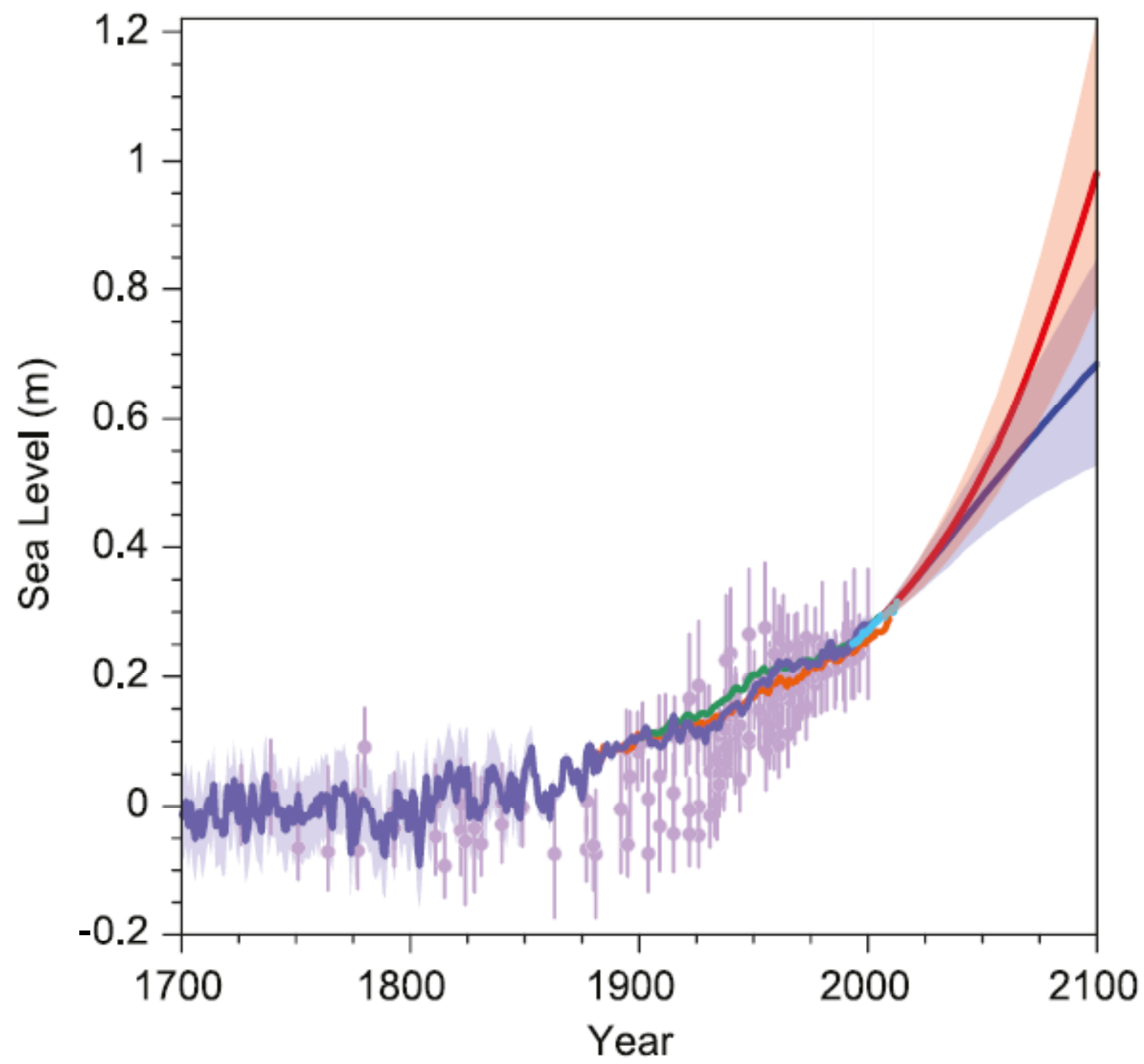

1223 Figure 1. Past and future sea-level rise. For the past, proxy data are shown in light purple and 1224 tide gauge data in blue. For the future, the IPCC projections for very high emissions (red, 1225 RCP8.5 scenario) and very low emissions (blue, RCP2.6 scenario) are shown (source: IPCC, 1226 2014, AR5 - Fig. 13.27). Sea-level values on the y-axis are shifted by the mean sea level 1227 between 1700 and 1850 (about $20 \mathrm{~cm}$ below mean sea level). 
Land area (thousands $\mathrm{km}^{2}$ ) Population (millions) GDP (US\$ billion)

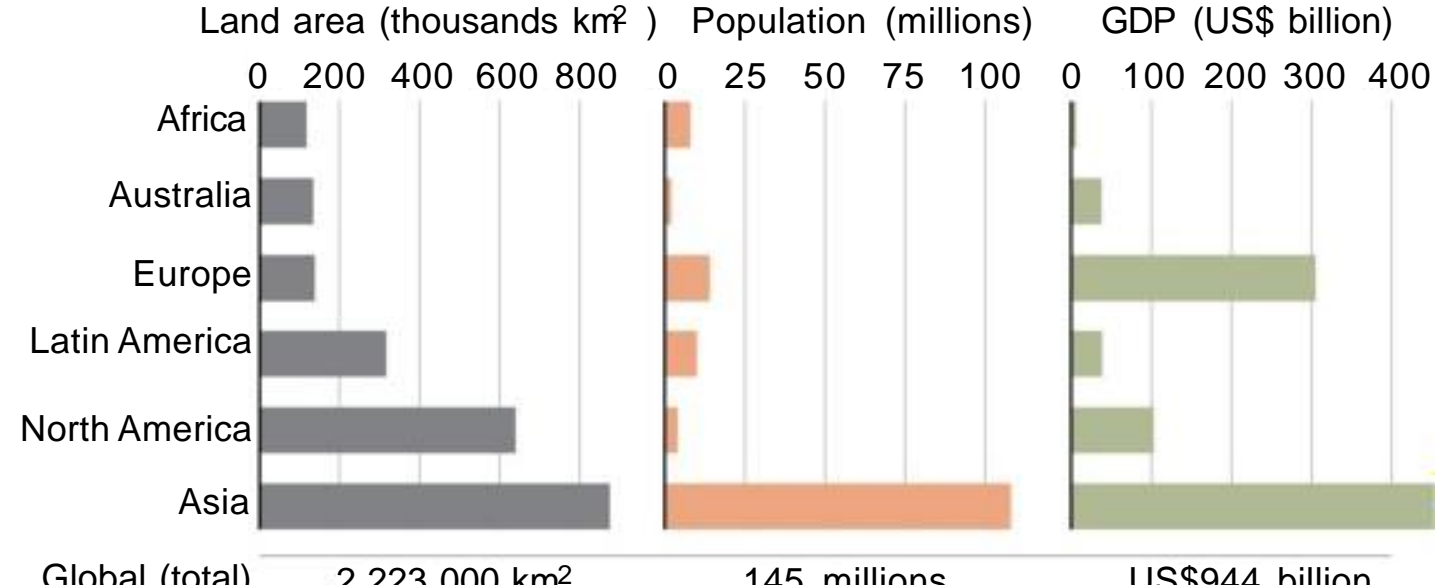

1229

Global (total) $2223000 \mathrm{~km}^{2}$

145 millions

US\$944 billion

1230 Figure 2. Population, area, and economy affected by a $1 \mathrm{~m}$ rise in sea level (global and

1231 regional estimates, based on the 2006 situation; source: Anthoff et al., 2006).

1232

1233

(A)

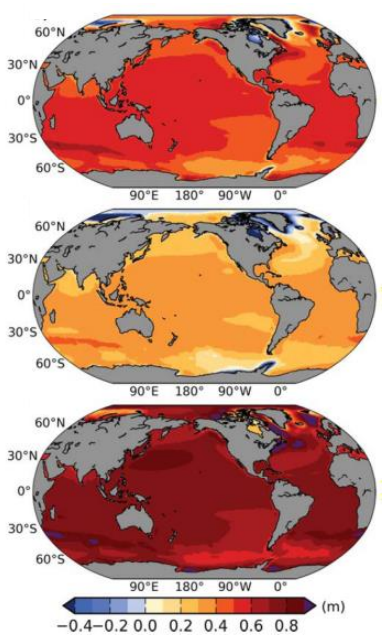

(B)
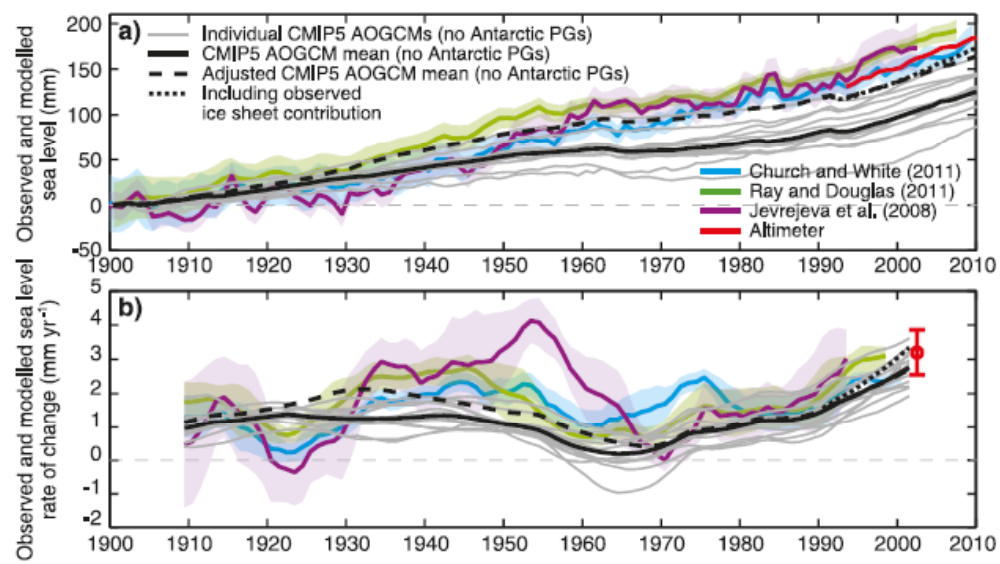

1234 Figure 3. (A) Maps of sea-level changes up to the period 2081-2100 for the RCP4.5 scenario.

1235 The top panel shows the model mean with an average of $50 \mathrm{~cm}$ global rise, and the middle

1236 and lower panels show, respectively, the low and high ends of the uncertainty range for this

1237 scenario (source: IPCC, 2014; AR5 - fig. 13.19). (B) Modelled (colours) versus observed

1238 (black) global sea-level rise: (a) the observed and modelled sea levels for 1900-2010; and (b)

1239 the rates of sea-level change for the same period, with the satellite altimeter data shown as a

1240 red dot for the rate in the twentieth first century (source: IPCC, 2014; AR5 - fig. 13.7). 


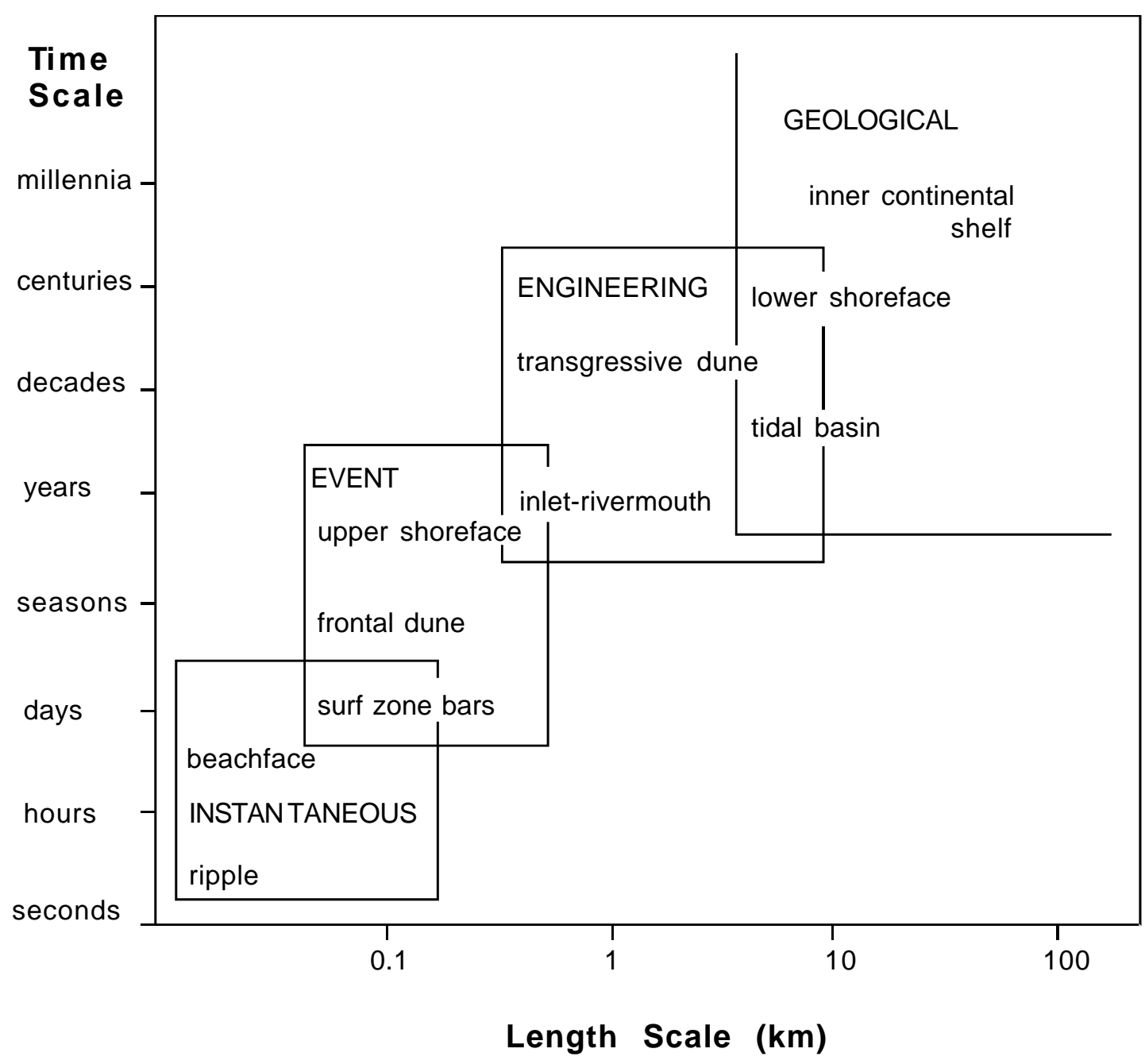

1242 Figure 4. Definitions of the spatial and temporal scales involved in coastal evolution. Large-

1243 scale coastal landforms evolve over long time scales, whereas small-scale coastal features

1244 respond over short time scales (adapted from Cowell and Thom, 1994).

1245
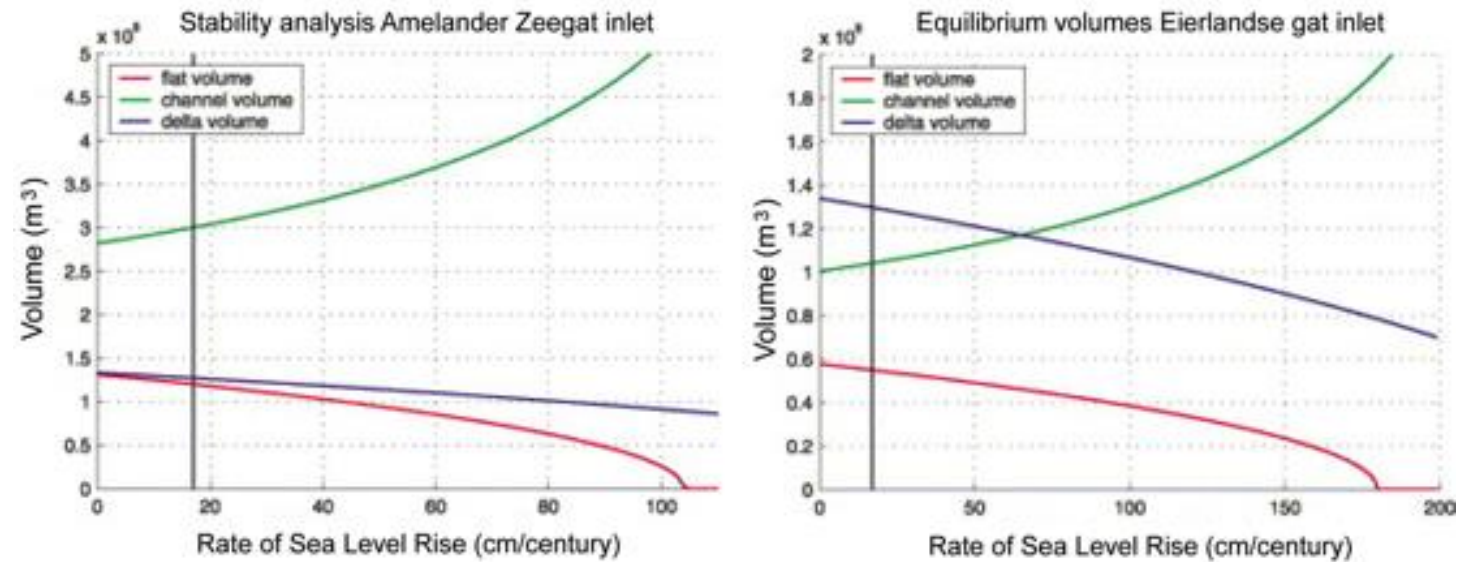

Figure 5. Dynamic equilibrium volumes of tidal inlet elements (see text in section 4.1) as a

1248 function of SLR rate for Amelander Zeegat and Eierlandse Gat. The vertical line in each case 
1250 (source: van Goor et al., 2003).

1251

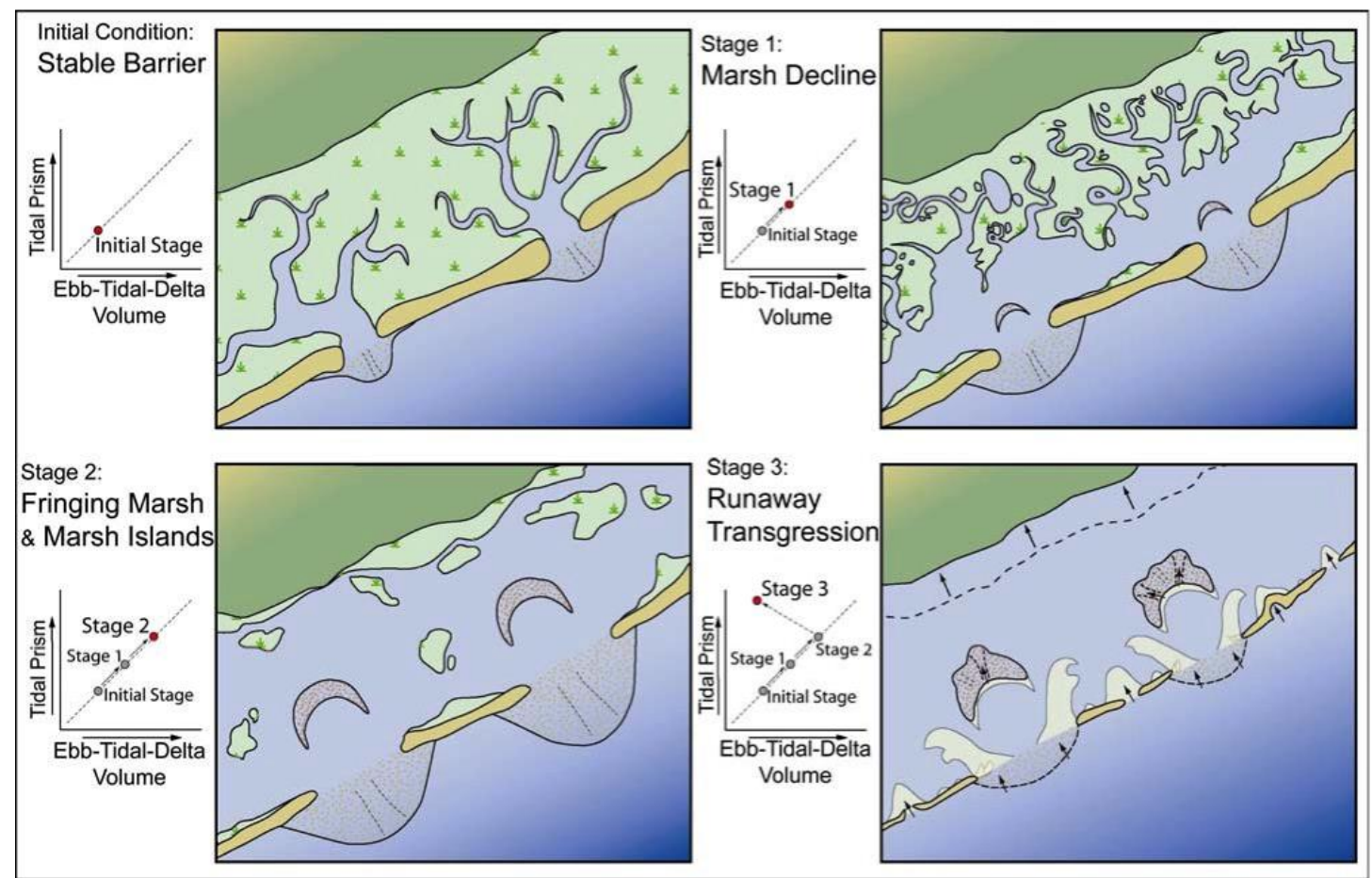

1252

1253 Figure 6. Conceptual model of mixed-energy barrier coast evolution in a regime of

1254 accelerating SLR (source: FitzGerald et al., 2006).

1255

1256

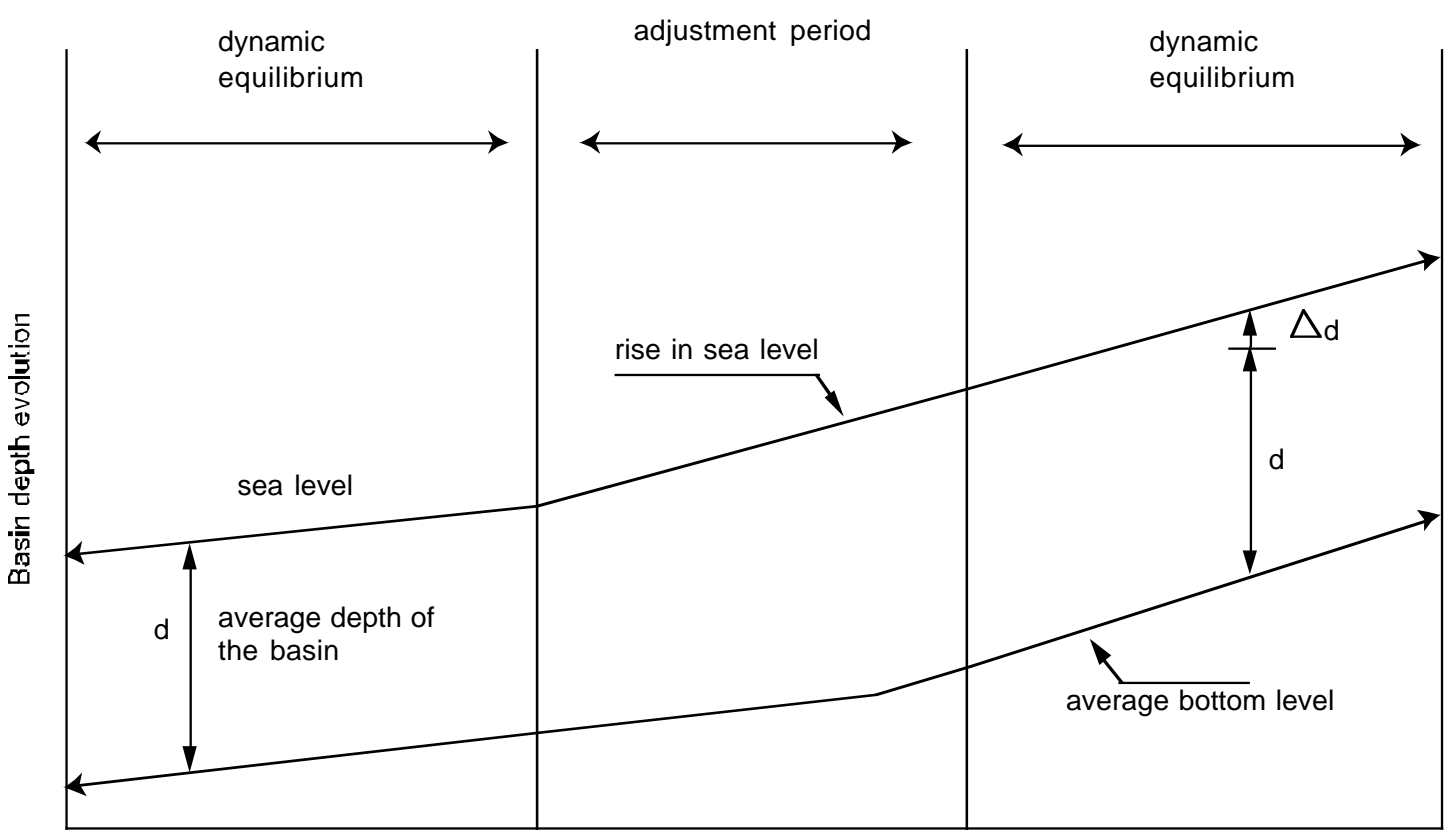

Speed of rise in sea level ( $m$ per century)

1258 Figure 7. Adaptive behaviour of tidal basins with changes varying over time (source: Louters 


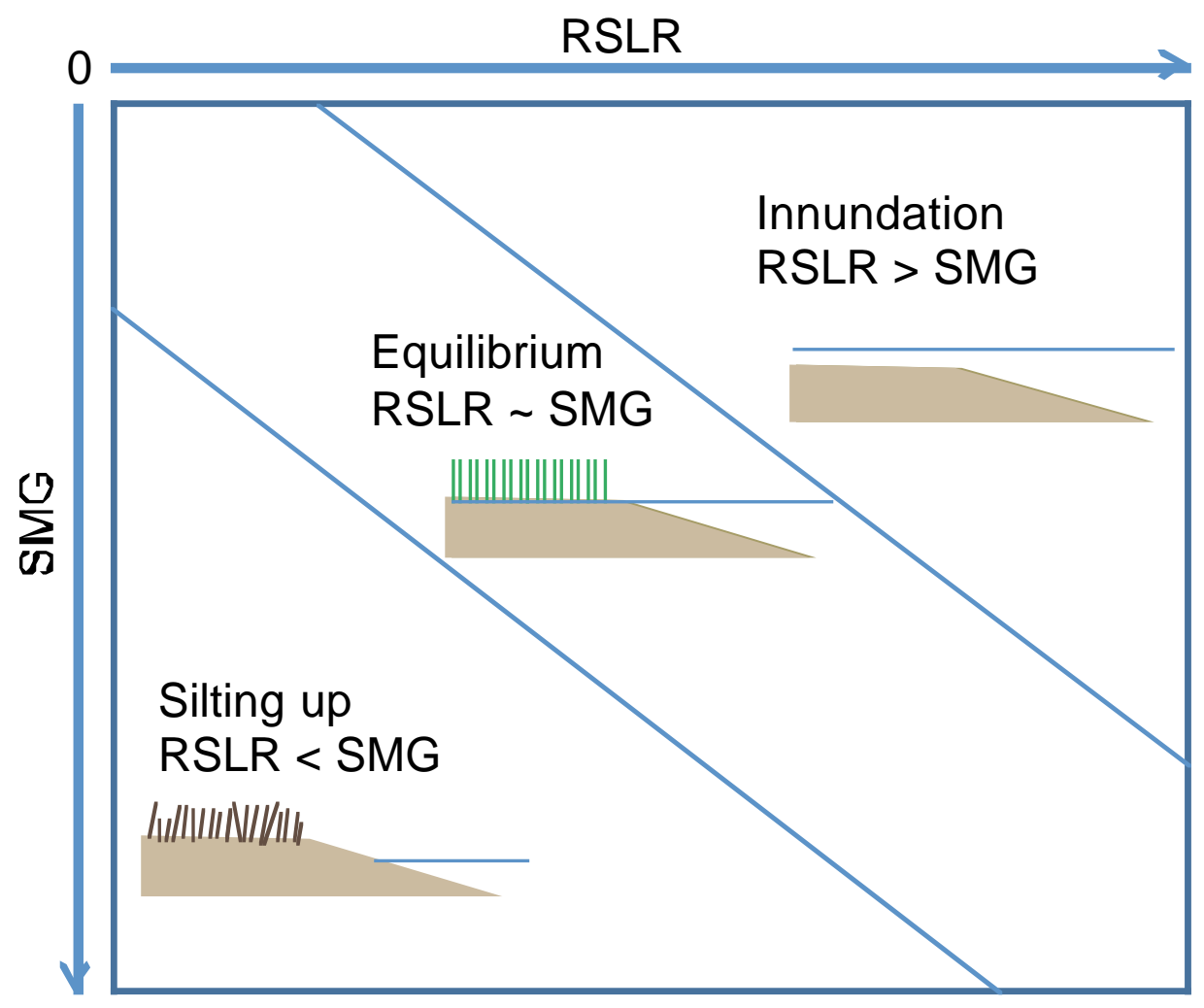

1262 Figure 8. Conceptual scheme showing salt marsh response to relative sea level rise (RSLR) 1263 and salt marsh growth (SMG).

1264 


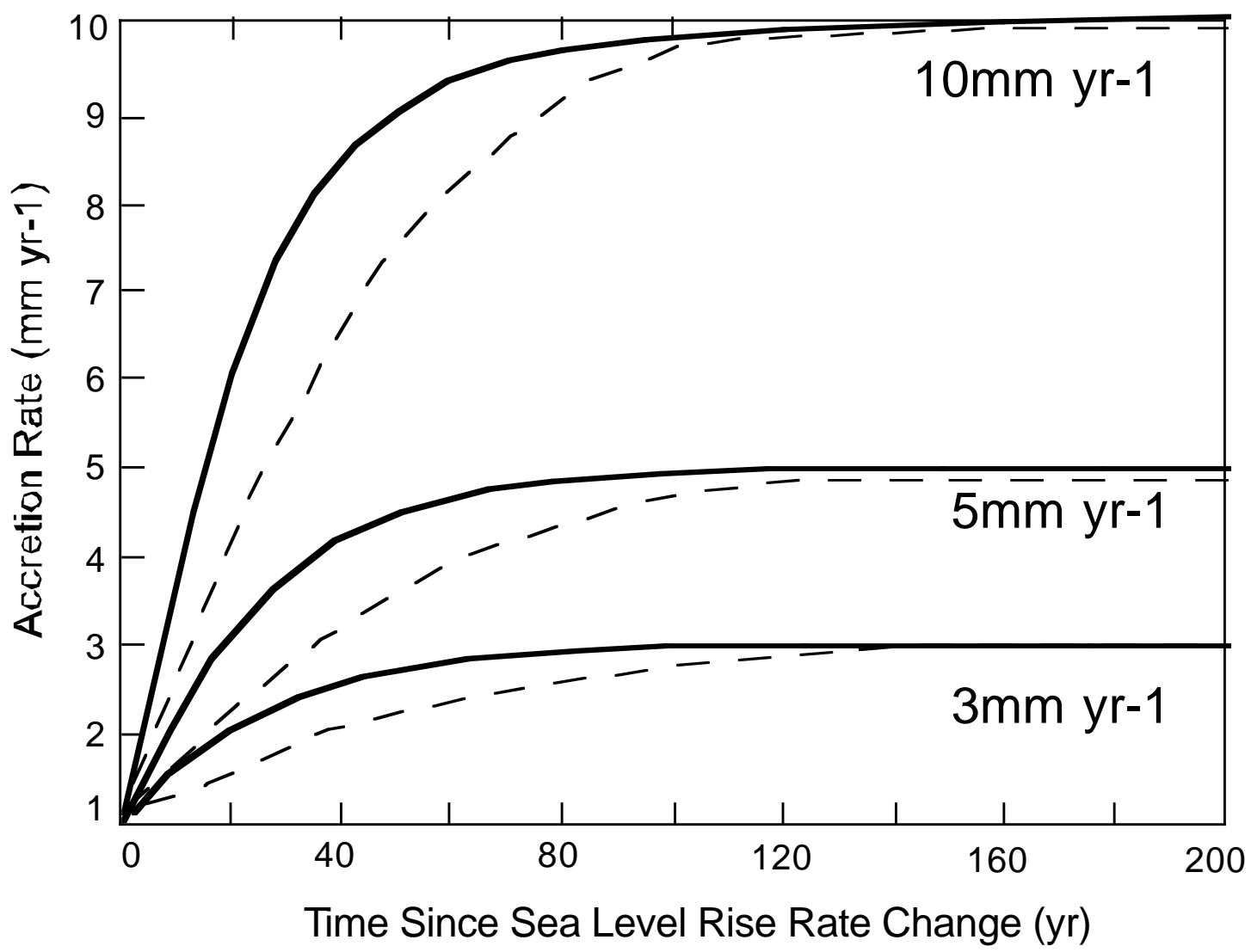

Figure 9. The response of modelled accretion rates to step changes in the rate of RSLR.

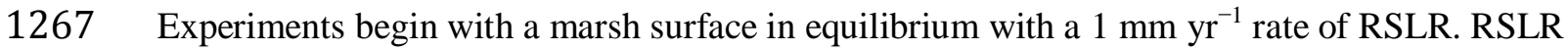
1268 rates increase abruptly to 3, 5, or $10 \mathrm{~mm} \mathrm{yr}^{-1}$ at time zero. Black line: Morris model (Morris et 1269 al., 2002); dashed line: Temmerman model (adapted from Kirwan and Temmerman 2009).

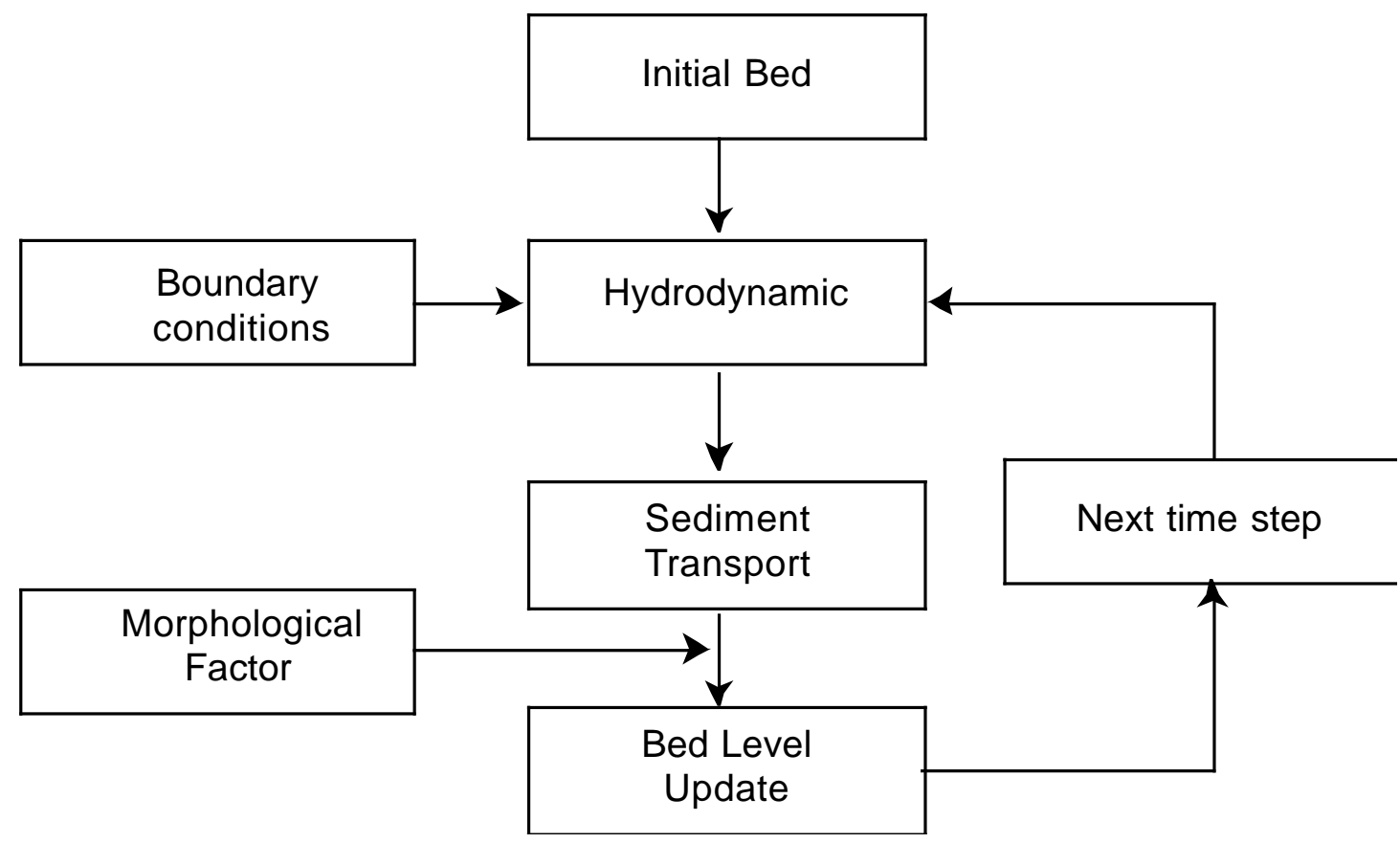


1272 Figure 10. Schematized diagram of the morphological model in Delft3D (source: Dissanayake 1273 et al., 2009). 